\title{
Dynamic Modeling for Product Family Evolution Combined with Artificial Neural Network Based Forecasting Model: A Study of iPhone Evolution
}

This paper was downloaded from TechRxiv (https://www.techrxiv.org).

\section{LICENSE}

CC BY 4.0

SUBMISSION DATE / POSTED DATE

$21-12-2021 / 22-12-2021$

\section{CITATION}

Biswas, Sumana; Ali, Ismail; Chakrabortty, Ripon; Turan, Hasan Hüseyin; Elsawah, Sondoss; Ryan, Michael J. (2021): Dynamic Modeling for Product Family Evolution Combined with Artificial Neural Network Based Forecasting Model: A Study of iPhone Evolution. TechRxiv. Preprint.

https://doi.org/10.36227/techrxiv.17304299.v1

$\mathrm{DOI}$

10.36227/techrxiv.17304299.v1 


\title{
Dynamic Modeling for Product Family Evolution Combined with Artificial Neural Network Based Forecasting Model: A Study of iPhone Evolution
}

\author{
Sumana Biswas, Ismail M. Ali, Ripon K. Chakrabortty, Hasan Hüseyin Turan, Sondoss Elsawah, Michael J. Ryan \\ Capability Systems Centre, University of New South Wales, Canberra, Australia
}

\begin{abstract}
Products continuously evolve over time. Realizing the pattern of product family evolution along with proper estimation of features for future products has been regarded as a critical issue for business success. Focusing on this issue, a dynamic model for product family evolution combined with forecasting is proposed in this research work. The proposed model considers the influence of market demand, customer needs and technological requirements that are time-dependent. The methodology is a four-phase model. In this model the evaluations of product family evolution are based on the Grey Relational Analysis and Fuzzy Analytical Hierarchy Process. Sensitivity is performed to investigate the reliability of the model. In addition, a data-driven neural network-based forecasting model is proposed that can forecast the specification of the most influential features of future product with a reasonable accuracy. This forecasting model utilizes the information of the previous generation's product. For each phase, the effectiveness of the developed approach is demonstrated with numerical simulation results and validated with a case study of Apple's iPhone product family. The case study shows that the approach is very effective to identify the most influential key design features and best performed products that will influence the evolution design of future product.
\end{abstract}

Index Terms-Product family evolution; Dynamic model; Neural network; Forecasting model; Grey relational analysis; Fuzzy analytical hierarchy process

\section{INTRODUCTION}

Industries generally design products in a cost-effective way and aim to deliver product with higher quality, innovative design, and mass customization [1]. They are facing challenges to fulfill different customer demands without compromising the effectiveness, efficiency, and profit. In a global competitive market, coping with technological advancement that changes over time is another key challenges for those manufacturing companies.

Many strategies have been developed in recent decades including modular design, unit design, and product family. From those strategies, product family design has received wide attention by researchers. The basis for product family development is the evaluation of product family evolution.

The term evolution comes from biological science. The evolution of living species means change in the gene pool of a population from generation to generation by such processes as mutation, natural selection and adaptation under a given environment or ecosystem [2,3]. Like living species, evolution

Corresponding author: Sumana Biswas Email address: sumana.biswas@adfa.edu.au

Preprint submitted in Technological Forecasting and Social Change also occurs in the life cycle of product. The development of product family is dynamic and, to adopt the dynamic environments, different variety of products emerges in the market over time. This adapting process is addressed as product family evolution [1].

Generally, in continuous market competition, new product variants are generated by upgrading or improving the previous products or generating an entirely new generation product by substituting the old generation products. According to Hou et al. [1], the structural changes of a product family is of two kinds; one is mutation where a big change happens in the product family and the other one is gradient. In mutation, new technology, material, and features appear and a new generation of product family emerges in the market. In gradient, the structure of the product family gradually changes, and new members or representatives of the family arrive that explore the horizontal diversity for the product family. Therefore, the product family constantly changes with time and, at the same time, it evolves along with the drive force to improve the performance of the product from one generation to another. Fig. 1 shows the time dependent evolution process of product family.

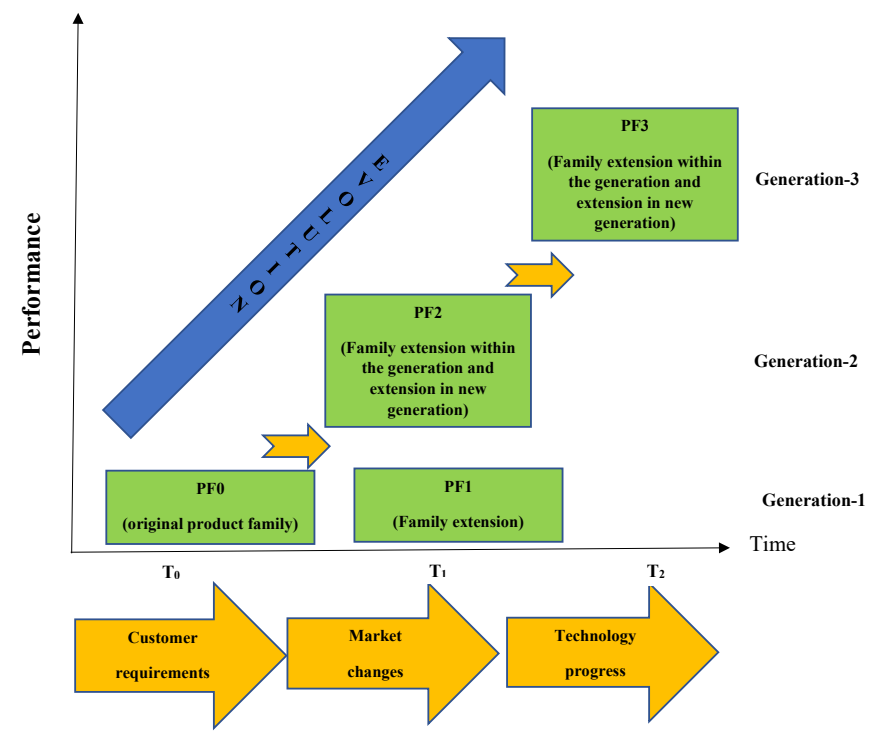

Fig. 1: Time dependent product family evolution

Usually, the evolution of a product family ensures the continuous growth of the product [4]. It may ensure reduction 
in development cost, improvement of the speed and reliability of product development and enhance the variability of business decisions [5]. Therefore, product family evolution is very significant in product family development, and sustaining profit and growth in the competitive markets depends on the information regarding product family evolution.

For product family development and product family evolution, designers need to consider numerous factors, their interactions, and how they affect product design. The major drive force includes market conditions, customer requirements and technology requirements $[1,6]$. The dynamic environments created by these three major factors influence the product family and its evolution over time. For example, products such as automobiles or smart phones have many product series with various configurations in the product family in order to keep up with changing technologies, customer needs and preferences and market growth and demand [7]. The evolution of product as well as the evolution of product family can also be considered as the result of adaptation to customer demands and technologies to meet the present market niche.

Product competition rapidly changes due to the dynamic nature of market environments such as the release of new products, withdrawal of the outdated ones and social changes [8]. By Yoon et al. [9] technological opportunities create new market for industries. Technological obsolescence is an important concern for the design of products that are long lifetime (e.g., freight trucks, industrial workstations) or have quick turnovers (e.g., cell phones, computers) [10]. Hence, in the evolution of a product family, the technological requirements are very significant factors that must need to be taken into account.

Product family evolution plays a key role in the development of new product variants. For the development of a new product variant, it is very important for a manager in terms of decision making to identify the most influential design features and best performed products that will dominate the future market. Hence, forecasting the design specification of those influential design features is crucial.

Numerous research $[1,10]$ efforts have considered different driving factors and their impact on product family evolution. However, there is little research on the evaluation of product family evolution considering together the three driving forces (market demand, customer requirements and technological requirements) that are dynamic in nature. In addition, research based on design features and the combination of the evaluation of design features and the evaluation of products is still not enough in the field of product family evolution.

Very few research addresses the forecasting in regards of product family evolution and they applied the conventional approaches such as cladistics for forecasting. However, accurate forecasting is still a difficult task because of the highly nonlinear and complex nature of product data.

Recent research activities in artificial neural networks (ANNs) have shown that ANNs have powerful forecasting capabilities. Several distinguishing features mean that ANNs are valuable and attractive alternative tools for forecasting [11]. Therefore, forecasting considering the ANN method are well suited for problems such as product family evolution whose solutions require knowledge that is difficult to specify but for which there are available data.

To alleviate the challenges associated with the evaluation of product family evolution and forecasting, this paper presents a dynamic model for product family evolution combined with an artificial neural network (ANN) based forecasting model. In the field of product family evolution the combination of forecasting model with the evolution model is new. The modeling of this research work is a four-phase approach: information phase, construction phase, evaluation phase and forecasting phase. The first phase collects the information of all previous generations of a certain product family. Product design specification and a set of key design features of the specified product is also created in this phase. After getting the information regarding all generation's product, an evolution graph is generated in the construction phase. This evolution graph applies the generation mechanism rules. It is very simple, and it can easily explain the evolution process of the product family from generation to generation. At the evaluation phase, evaluation of design features and evaluation of products are performed simultaneously. Grey relational analysis (GRA) with fuzzy Analytical Hierarchy Process (fuzzy AHP) is applied for the evaluation of product family evolution. The evaluation results provide the overall comprehensive performance of the product family as well as identify the influential features that have a significant impact on the evolving design of the future product. It also assists the manager in future product expansion by identifying important design features from many features as well as classifying best performed product from the product family. The final phase is the forecasting phase, where an ANN is used to forecast what would be the specification of some key design features of future products. This model uses actual product historical data to provide better solutions. It is assumed that the proposed model is applicable for the existing products or product families in the market. Our proposed approach is data dependent, it uses the historical information of the products of a product family. Hence, it is not convenient to apply this approach for a completely new product in the market or product innovation. It is convenient to apply for the existing product family in the market.

The three dynamic factors; market demand, customer requirements and technological requirements have great impact on product evolution and this study considers all these three dynamic factors together in the modelling. The main significant part of this study is the incorporation of forecasting model with the evaluation model. Hence, this paper provides designers with the capability to evaluate product family evolution as well as the capability to forecast future product. To the best of our knowledge, the idea of the combination of GRA, Fuzzy AHP and ANN in the field of product family evolution is innovative. This study also proposes an evolution graph that is easy to understand. Future researcher or designer can easily use this graph to comprehend the relationship between products. In addition, this paper proposes an approach to find out the best performed product as well as the important features of a product family from one dynamic modelling. The main contributions of the paper are as follows:

- A dynamic model of feature-based product family evo- 
lution is proposed that consider the three driving factors: (i) Market demand, (ii) Customer requirements and (iii) Technology requirements all together.

- An evolution graph is introduced by applying generation mechanism. The evolution graph is very simple and easy to elucidate the evolution pattern of a product family.

- The proposed dynamic model evaluates the product design features and products simultaneously that can identify the most influential features as well as best performed products from a large number of design features and products respectively. It helps the manager in decision making about future product development.

- An ANN based forecasting model is incorporated with the evaluation model to determine the design information of important features of future product, which are critical in their design.

The rest of the paper is organized as follows. Section II reviews the studies that address the relevant research efforts on product family evolution and neural network based forecasting models. The details of the case study is discussed in Section III. Section IV outlines the problem statement. Section V describes the proposed four-phase methodology. Section VI discusses the sensitivity analysis at different stages of the dynamic model. The results and discussions are provided in Section VII. Section VIII discusses the managerial implications of this study. Finally, the conclusions and directions of future research are given in Section IX.

\section{LiTERATURE REVIEW}

Numerous research efforts have been undertaken to characterize, understand, quantify, and generate models for product family evolution. The earlier studies such as mapping of product family evolution $[12,13]$, platform leveraging strategy $[14,15]$, categorization of product family evolution [16] generally represent the product family evolution in strategic marketing and management platforms to provide managerial directions [17]. Later other studies [18,19] developed a methodology or framework focuses on modeling the evolving properties in product families. Table A.1 in the Appendix summarizes the literature regarding product family evolution and forecasting. The research approaches related to product family evolution are described in the following subsections.

\section{A. Dynamic modeling \& framework for product family evo- lution}

As the characteristics of evolution of product family is dynamic, several researcher considered product family evolution as a dynamic model. Park and Kremer [4] developed a dynamic model that can effectively show the structural changes of a product family over time. A product family evolution model was proposed by Wang et al. [20] as an extension of the core product model (CPM), which consists of family, evolution, and rationale. Duo et al. [21] proposed an iterative product design through group opinion evolution. The authors integrated the Hegselmann-Krause model into product improvement process and developed a dynamic model. This dynamic model simultaneously converges the evolution of customers' opinions, professional designers' opinions, and the product scheme. To develop a model of the evolution of product competition relations, Xie et al. [8] developed a data driven dynamic network analysis approach. They proposed a separate temporal exponential random graph mode (STERGM) approach for modeling and consider the impact of endogenous variables as well as exogenous variables on the formation and dissolution of product competitions separately. This approach is effective to support engineering design decisions and companies' strategic decision making when improving existing products or releasing new products. Technology evolution theory of TRIZ (in English: Theory of Inventive Problem Solving) is a very effective approach for product family evolution that uses a set of technological factors of evolution [22]. $\mathrm{Xu}$ et al. [18] introduced the technology evolution theory of TRIZ to study the product family architecture evolution process. This study can be applied to improve the rational and modularization level of product family architecture. It also enhanced the capability of mass customization. Shao et al. [23] analyzed the evolution process of a product family architecture at the component level and proposed the concept of a structure semantic unit (SSU) to analyze the evolution of components on a product family architecture. Through consumption analysis, they set the threshold value in order to determine whether a component need to be deleted from product family architecture, or a new part needs to be added there. [23-26] also conducted the modeling of product family evolution based on product family architecture view to reflect dynamic properties and conditions around a product.

Network based approaches are another popular modeling technique to describe product family evolution. Based on different mechanisms of networks evolution, Le et al. [27] developed a generative network computational model for product evolution. This evolutionary model helps to identify not only the extent of increase in complexity over time, but also the mechanisms through which the complexity increases. Kijung Park [17] investigated structural properties and patterns in a product family architecture across generations and time periods and modelled its changing behaviors under dynamic product environment. Li et al. [28] proposed a dynamic product design evolution analysis model based on the Bayesian network for reasoning on product function evolution. In this model, the authors considered different structural and functional design factors such as customer satisfaction, manufacturing cost, sale price, market sales etc. Authors used a quantitative reasoning approach to identify, how customer demands of the product and structural design and dynamic design schemes are influenced by each other.

The above research on product family evolution considers different drive force during product family development. However, there is still a lack of research on product family evolution considering the three dynamic factors (customer requirements, market demand and technological requirements) all together.

\section{B. Other approaches for product family evolution}

Product family evolution can be described as a retrospective study based on the application of the generational variety 
index [7]. A comprehensive evaluation model based on gray conjunction degree was established by Hou et al. [1]. In this paper, they analysed various dynamic factors of product family evolution. From the perspective of time and space, the dynamic and static relation of product family evolution was summarized by the authors. They also considered the chaotic indicators in product family evolution that are largely limited to the following three categories: customer satisfaction degree (CSD), economics, and agility and personalization (AP), which are affected and restricted by each other. Agent-based method (ABM) can be utilized to reveal the logic of product evolution that is affected by the producer's routine, customer's preference, and complementarity of the product features [29]. Kim et al. [29] identified how fast products evolve and which conditions drive the velocity of the product evolution. Product family evolution can be compared with biological evolutionary principles and can be graphically explained by a phylogenetic tree of product family [30].

Very little research has been undertaken on design feature based product family [31]. Zhang et al. [31] developed a model of feature-centred product family for the holistic description of the evolution process of a product family to support rapid development of new products with hybrid innovations. However, their proposed work only considers market requirements and customer requirements as driving force and disregard technological requirements.

\section{Forecasting product family evolution}

Forecasting is a significant part of product family evolution to develop new products. Cao et al. [32] proposed the product innovation process model based on function evolution and forecasting, which provides a systematic approach to product innovation from the functional design angle. The authors proposed division stages and laws of function evolution that direct function design. They also modeled the influence of changing demand and systems on the evolution of product function. Forecasting product evolution and sales can also be modeled as a function of technological changes, market growth, and market preferences [33]. This proposed model can predict market growth, generation substitution and it also has the capacity to predict technology evolution. AlGeddawy and ElMaraghy [34] developed a prediction model to present a closer integration between manufacturing systems and the manufactured products, not only in the current planning horizon, but also throughout the course of their progressive development, evolution and interaction. A forecast method for the increment of component numbers and parts based on the increment of products is also presented by Liu et al. [26], who applied a directed complex network to model the structure.

Generally, forecasting problems are complex with a significant number of underlying factors and traditional forecasting models face difficulties in terms of taking account of those complicated, non-linear relationships [35].

In the last few years, ANN-based methods have become very popular in real-world applications such as forecasting, estimation, supply chain management etc. ANN is nonlinear model that is easy to use and understand compared with statistical methods. ANN is non-parametric model while most of statistical methods are parametric models that need a greater background of statistics. Neural networks allow arbitrary nonlinear relations between the independent and dependent variables, and it also allows all possible interactions between the dependent variables [36]. On the other hand, standard statistical approaches require additional modeling to allow this flexibility.

In this context, ANN approaches are very promising for forecasting purposes [37]. Neural networks can deal with incomplete information with high accuracy and have the capability of self-adaptability [38]. Currently, the ANN approach is one of the most commonly used methods for forecasting [3843]. Obafemi et al. [44] provided a review by highlighting the stages in ANN modeling and it's application in forecasting purposes. Biswas et al. [45] developed a neural network forecasting model for mission planning. Lee et al. [46] applied statistical and machine learning based approach for prediction, prior to new product launch. Golmohammadi [47] developed a neural network model to capture and represent the preferences of decision makers. This model can be applied for a multiattribute decision making problems and can be used for future ranking or selection without manager's judgment effort. A systematic approach to the development of feed-forward ANN-based forecasting models was presented by Maier and Dandy [48] with application for modeling environmental systems. However, as far as we know, no research considered ANN to address forecasting in product family evolution. Thus, to develop a forecasting model for a complex system such as product family application, the ANN technique can be a reliable and effective method and thus has been employed in this work.

\section{Observation from literature review}

Recent research addressing product family evolution and forecasting shows that the evolution of product family as well as forecasting about future product are recognized as potential research areas requiring more in-depth analysis. From the studies reviewed in Section II, it is clear that an extensive amount of research has been undertaken in the field of product family evolution and forecasting. However, dynamic modeling which simultaneously incorporates the three drive forces (i.e., market demand, customer requirements and technological requirements) to evaluate the product performance as well as evaluate the product design features regarding feature based product family evolution is still a promising research direction. In addition, to our knowledge, no existing research evaluates the design features and product simultaneously for product family evolution.

From the literature review, it is also observed that the development of ANN-based forecasting model is not addressed in the context of product family evolution. The forecasting model will not only predict the outcome of the new product variant but also helps mangers to make decisions regarding the overall strategy. 


\section{CASE STUdy}

Smartphones have become an essential part of human daily life. The smartphone is one of the info-communication devices that changes rapidly over time as they are very sensitive to customer requirements and new technologies [30]. Hence, we demonstrate the applicability of our approach in a case study motivated by smartphone evolution. In our study, the Apple iPhone is considered as an example of a product to analyse product family evolution. Apple iPhone has been in the market for an extended period of time since June 2007 and new products are still released almost every year. Apple iPhone has high a prevalence in modern society. Apple's customers are largely viewed to be loyal, and isolated from other brands [49-51], so their high market share, rapid technological improvement and diversity means that without considering other competitors in the category they are a good candidate for this study. With the development of personalised and diversified and technological advancement of Apple iPhone's, this product not only shows the relationship within the generation but also with new generations. In this work, we consider the Apple iPhone from the first generation to the latest generation (April 2020). Data about all generations was collected from a number of open web databases [52-60]. Secondary data have been used in this study.

\section{Problem Statement}

In a product family there are several types of products and all products have a number of features. All design features does not have the same impact or influence on the evolution as well as on the development of future product. Identify the influential features and forecast their design specification is crucial and it has a great impact on decision making. The generic flow diagram explaining the problem and the proposed solution methodology is shown in Fig. 2. The details of the problem statement are given below:

Given is a product family consisting of $N_{p}$ number of products. Specifications of those products, and design features are also given to evaluate the evolution of the product family and forecast some design information of some influential features. The overall problem is divided into four phases, with each phase having its own sub-problems described as follows:

\section{A. Information Phase}

In this phase, data regarding the products of a specific product family is collected from different sources. Here, data such as product name, product design specifications, product features, release date, discontinuity date etc. are collected.

- Gather product-related information

Details of this phase are discussed in Methodology Section.

\section{B. Construction Phase}

In this phase, the relation among products of a product family is established through an evolution graph.

- Develop evolution graph

Details of this phase is discussed in Methodology Section.

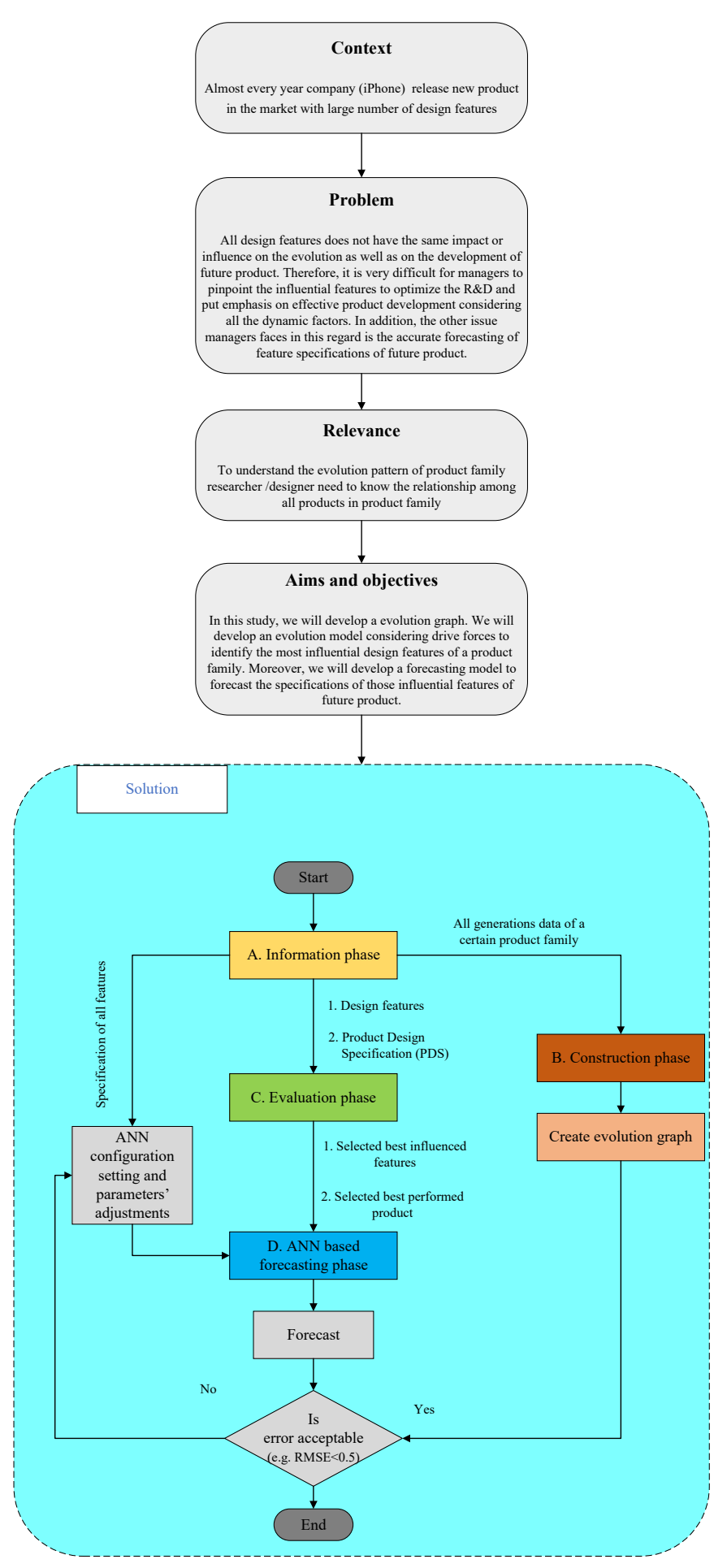

Fig. 2: A generic flowchart for problem definition and solution methodology

\section{Evaluation Phase}

An application of the mathematical technique to facilitate the selection of the best alternative among a set of possible alternatives will allow reducing the probability of a wrong choice [61]. The set of ' $n$ ' key design features (alternatives) denoted, say by $a_{1}, a_{2}, \ldots, a_{n}$ can be identified by analysing 
the design features of the product family that significantly influence the product's functions, performance and quality. The set of ' $m$ ' Product design specifications (PDS) are denoted by $c_{1}, c_{2}, . . c_{j}, \ldots, c_{m}$. The PDS is a detailed document providing a list of points regarding a product or process. Here, PDSs are considered as the criteria.

A formal framework for comparison and ranking of the alternatives $a_{i}(\mathrm{i}=1,2, \ldots \mathrm{n})$ is the methodology of MCDM. It allows inter-alternative comparisons of $a_{i}$ by applying a set of criteria $c_{1}, c_{2}, . . c_{j}, . . c_{m}$. A problem statement of MCDM is $n$-by- $m$ decision-making matrix (DM). Its element $d m_{i j}$ represents a value of the criterion $c_{j}$ related to the alternative $a_{i}$.

$$
D M=\left[\begin{array}{cccc}
d m_{11} & d m_{12} & \ldots & d m_{1 m} \\
d m_{21} & d m_{22} & \ldots & d m_{2 m} \\
\vdots & \vdots & \ddots & \vdots \\
d m_{n 1} & d m_{n 2} & \ldots & d m_{n m}
\end{array}\right]
$$

A wide variety of MCDM methods allows ranking the alternatives $a_{i}$ by applying both quantitative and qualitative criteria $c_{j}$.

- Calculate criteria weights.

- Generate the ranking of the alternatives

In the Methodology section it is considered that,

$a_{1}, a_{2}, \ldots, a_{n}=f_{1}, f_{2}, \ldots, f_{n}$ and

$c_{1}, c_{2}, \ldots, c_{m}=P D S_{1}, P D S_{2}, \ldots, P D S_{m}$

\section{ANN-based forecasting Phase}

In the final phase, an ANN-based forecasting model is developed. Given an information set consisting of data related to previous products or product family and ' $N_{f}$ ' number of design features selected from the previous phase is considered-

- Develop an approach to determine the product specifications of the selected features.

In this work, GRA is used to evaluate the evolution of product family where fuzzy AHP is integrated with the GRA to determine the weight of the criteria (PDS). That means GRA combined with fuzzy AHP determines which product as well as which features are dominating in the evolution process of product family.

On the other hand, ANN forecasts some design features of the future product. From the ranking of the evaluation (GRA combined with Fuzzy AHP) process, the ANN model selects the top ranked design features for forecasting. The ANN model considers the top ranked design features from the GRA combined with fuzzy AHP process to be forecasted for future product.

\section{Methodology}

The structure of the proposed methodology comprise four phases: A. Information phase, B. Construction phase, C. Evaluation phase and D. ANN based forecasting phase.

The information phase is the most significant part of the dynamic modeling problem, laying the foundation of the whole model. In this model, the construction phase and evaluation phase are parallel and independent. In the evaluation phase, two evaluations are performed:

- C.1 Evaluation of design features, and

- C.2 Evaluation of products.

The final phase is dependent on the outcomes of the evaluation phase. In this ANN based forecasting phase, forecasting (about the design specification of future product features) is based on the outcome of the previous (evaluation) phases.

Each phase with their own subproblems is described as follows:

\section{A. Information phase}

The information phase is the first phase where history regarding the product is collected, and also driving forces and design features of the specific product are identified. This phase includes three tasks:

- A.1 Data collection.

- A.2 Identification of drive forces.

- A.3 Identification of design features.

The tasks are described below.

1) A.1 Data collection: Table A.2 shows the list of Apple iPhone product for all generations (2007 - April 2020). There are different types of data; numerical and categorical. Data has been reprocessed for this analysis. Here the dummy coding method [62] is used to convert the categorical input variable into a continuous variable.

2) A.2 Identification of drive forces: This part is divided in two steps:

- Step 1: Identify and create a set of dynamic factors for product family evolution

The set of dynamic factors that extracts the driving force information from customer requirements $(C)$, market demands $(M)$ and technology requirements $(T)$ of a certain product is denoted by ' $A$ '.

The ' $A$ ' is formed by combining comprehensive evaluation with clustering analysis, as follows:

$A=\left\{C_{1}, C_{2}, \ldots, C_{I}\right\} \cup\left\{M_{1}, M_{2}, \ldots, M_{J}\right\} \cup\left\{T_{1}, T_{2}, \ldots, T_{K}\right\}$

where $I, J$ and $K$ represent various customer requirements, market demands, and technological requirements, respectively. Fig. 3 shows some examples of drive forces related to a iPhone product family. From Fig. 3 (a) and (b) it is found that some of the drive forces of customer requirements and market demands are the same. However, there are also differences between them. Customer requirements are also known as customer demands. It is influenced by a customer's age, sex, culture, income, expectations, and the prices of competing goods in the market. Whereas market demand is influenced by the same factors of customer requirements, but on a broader scale - considering the community of national or international level and so on [63].

- Step 2: Create product design specification (PDS) for iPhone product family

At time $T_{i}$, the PDS is illustrated as follows: 


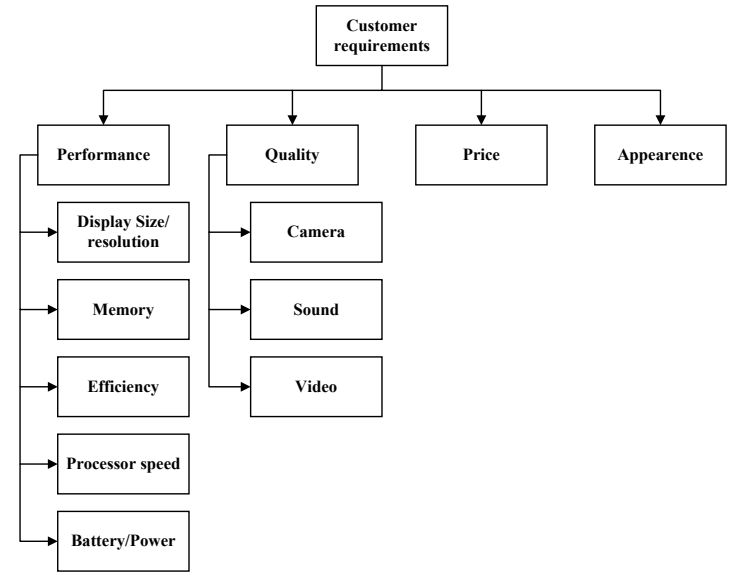

(a) Customer requirements

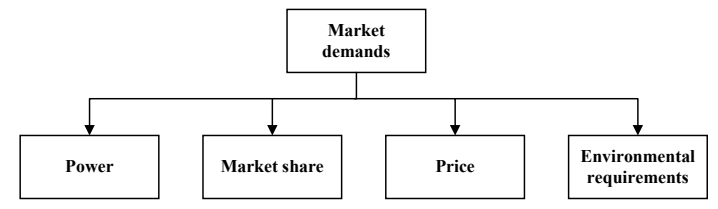

(b) Market demand

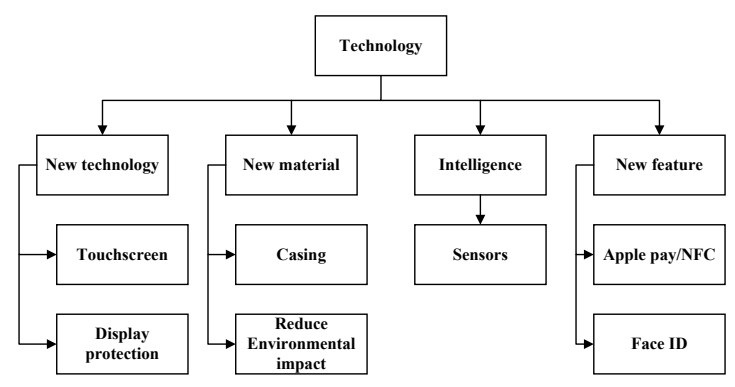

(c) Technology requirements

Fig. 3: Drive forces for iPhone product family

$$
P D S^{i}=D \times W^{T}
$$

$P D S^{i}=\left\{P D S_{1}, P D S_{2}, \ldots . P D S_{m}\right\}$, where $D=$ $\left[d_{1}, d_{2}, \ldots d_{n}\right]$ is the list of design elements of set ' $A$ ' (dynamic factors) and $W=\left[w_{1}, w_{2}, \ldots w_{n}\right]$ is the assigned weight for each element based on its degree of importance.

The PDS is a listing of the critical parameters, specifications and requirements for the product that is going to be designed [64] and is mainly driven by three major forces: customer demand, market changes and technological requirements. Table I shows the PDS for the Apple iPhone product family at this present time.

3) A.3 Identify design features: Key design features are important information related to the product design, which significantly influence the product's functions, performance, and quality. In business, a product feature is one of the distinguishing characteristics of a product or service that helps boost its appeal to potential buyers, and might be used to
TABLE I: LIST OF PDS

\begin{tabular}{cl}
\hline Number & PDS \\
\hline 1 & Display size \\
2 & Display resolution \\
3 & Touchscreen size \\
4 & Touchscreen technology \\
5 & Sound quality \\
6 & Processing speed \\
7 & Memory capacity \\
8 & Data transfer/Download speed \\
9 & Internet and connectivity (Wi-fi) speed \\
10 & Bluetooth \\
11 & Operating system \\
12 & Chipset \\
13 & Baseband memory \\
14 & Battery Performance \\
15 & GPS \\
16 & Camera resolution \\
17 & Video capability \\
18 & Casing (housing parts) /weight \\
19 & Protection \\
20 & Environmental Requirements \\
21 & Price \\
22 & Ease of use \\
23 & Size \\
24 & Sensors \\
25 & Impact on environments \\
26 & Number of SIM card \\
27 & Mobile phone safety \\
28 & Application/Apps \\
29 & Network \\
30 & Robustness \\
31 & Build/material \\
& \\
\hline
\end{tabular}

formulate a product marketing strategy that highlights the usefulness of the product to targeted potential consumers. The set of design feature $f^{i}$ is defined as follows:

$$
f^{i}=\left\{f_{1}, f_{2}, \ldots . f_{u}\right\}
$$

Table II shows some design features for Apple iPhone.

\section{TABLE II: LIST OF DESIGN FEATURES}

\begin{tabular}{cl}
\hline Number & Design features \\
\hline 1 & Display \\
2 & Touchscreen \\
3 & Sound system \\
4 & Processor/CPU \\
5 & GPU \\
6 & DRAM memory \\
7 & Flash memory \\
8 & Data transfer/Download speed \\
9 & Internet and connectivity \\
10 & Software \\
11 & Battery \\
12 & GPS \\
13 & Camera \\
14 & Outer casing \\
15 & Physical interfaces \\
16 & Screen protector \\
\hline
\end{tabular}

\section{B. Construction phase}

This phase includes two steps:

- B.1 Identify the relationship between products.

- B.2 Create evolution graph

In this phase, a product evolution graph is generated after identifying the relationship among products in the iPhone 
product family. A product evolution graph is a diagram that can be used for analysing the product development history [65]. Similar to the pedigree graph $[66,67]$, the product evolution graph shows the inheritance of genetic conditions among multiple generations. This phase is very significant to understand the evolution pattern of the product family from generation to generation.

From the details of the information phase, the predecessor and successor relationship (or inheritor relationship) as well as the offspring or siblings relationship among products, are identified. At the next stage, an evolution graph is constructed and presented graphically to describe the relationship. Fig. 4 presents the evolution graph of iPhone product family.
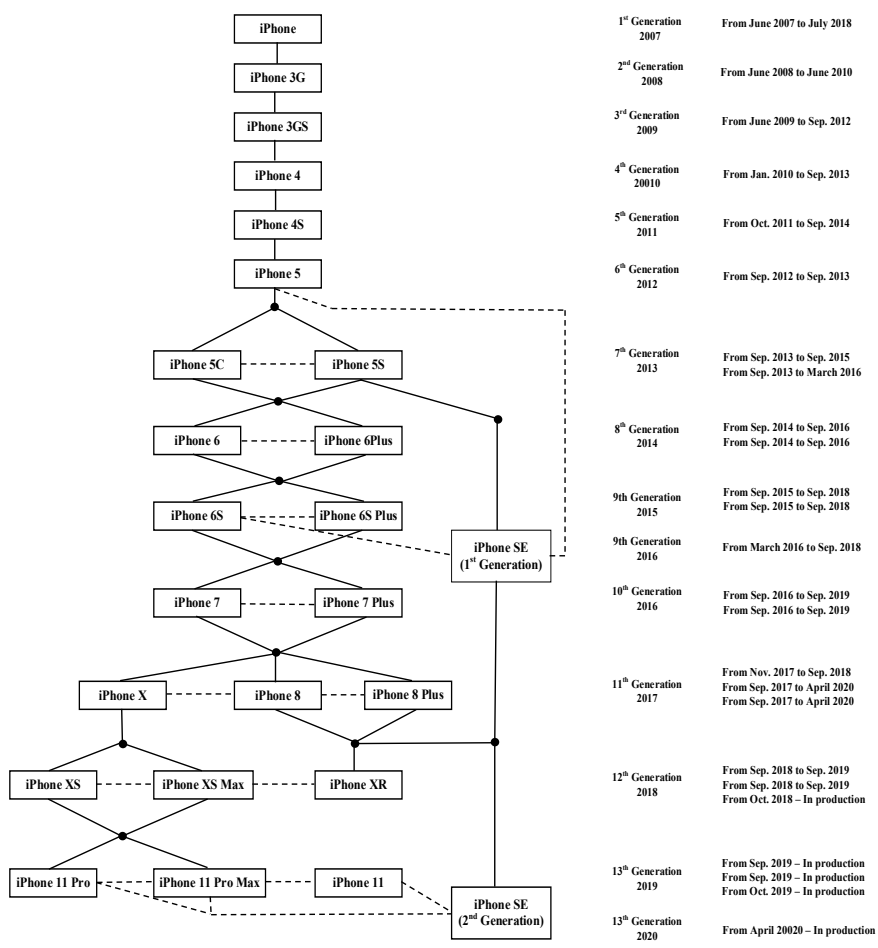

Fig. 4: Evolution graph of iPhone product family

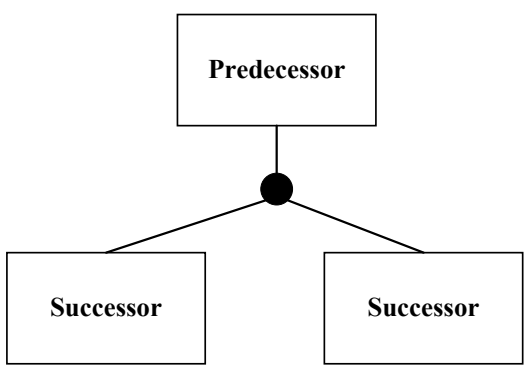

(a) Predecessor and successor relation

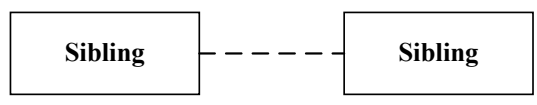

(b) Siblings relation

Fig. 5: Product variant generation mechanism
Fig. 4 shows the relationship among products of this product family. In Fig. 5 (a) the predecessor and successor relationship are illustrated by a solid line and in Fig. 5 (b) the sibling relationship is illustrated by dotted lines. For example, iPhone is the ancestor of all products. iPhone 5 is the predecessor of iPhone 5C and iPhone 5S and its successor are iPhone 6 and iPhone 6 Plus. There is a sibling relationship between iPhone $5 \mathrm{C}$ and iPhone $5 \mathrm{~S}$. iPhone $5 \mathrm{~S}$ is the predecessor of iPhone SE ( $1^{\text {st }}$ generation) and it is a sibling of iPhone 5 and iPhone $6 \mathrm{~S}$. Whereas, iPhone SE ( $1^{\text {st }}$ generation), iPhone 8 and iPhone 8 Plus are the predecessor of iPhone SE ( $2^{\text {nd }}$ generation) and iPhone 11, while iPhone 11 pro and iPhone 11 Pro Max are siblings. The same rules applied to other products as well. From the evolution graph, it is easily found that the product family of iPhone extended in a horizontal way and as well as diverse vertically from one generation to others.

Therefore, based on the relationship and by following the generation mechanism a new product variant can be added to the product family evolution graph.

\section{Evaluation phase}

In this phase, GRA [68] is applied for the comprehensive evaluation of iPhone product family evolution.

GRA is part of grey system theory proposed by Deng [68] and it is suitable for solving problems with complicated interrelationships between multiple factors and variables [69, 70]. Generally, the GRA method is used to quantitatively describe and compare the development tendency of a system [71]. Compared with other multi-criteria decision analysis, grey relational analysis has some merits in that it can deal with small data sample and needs small amount of calculation. etc. [72,73]. The biggest advantage of GRA is that it is an objective method of data analysis and does not require a large amount of data. Even with a small amount of data it can obtain reliable results. It can also be suitable for dealing with poor, incomplete, and uncertain information [74].

The relationship among influential drive forces in product family evolution are very complicated and the strength, size, and the order of the relationship among these factors or between the PDS vector and the design features set can be easily described by GRA [1].

The other reason to use GRA is that the accuracy of correlation matrix is important because it affects design scheme selection and evaluations. However, it is difficult to guarantee because it is established based on the accuracy of design knowledge and experience. To deal with this problem, GRA is used to avoid false correlation.

In case of the evaluation of design features, the first task is to construct a relationship matrix between the PDS and design features. On the other hand, for the evaluation of products, the first task is to construct a design matrix between products and design features. Please see Table S1 and Table S2 in the the supplementary file to see the relationship matrix and the design matrix respectively. The rest of the procedure are same for both evaluations. In this work, GRA is adopted from [75].

The drive forces can have different dimensions and magnitudes. In order to facilitate process analysis in product family 
evolution and ensure the reliability of the result, relative correlation analysis is utilized to compensate data deviation in absolute correlation analysis [1]. The analysis result is only related to the sequence change rate relative to the initial point, so the raw data in the evaluation is processed in a standardized way.

In product family, different feature have different types of data. Hence, for the grey relational generation, data is preprocessed [76,77]. After data preprocessing, to express the relationship between the ideal and actual normalized data of feature specifications, the grey relational coefficient is calculated [76].

Here, the reference vector $x_{0}$ is the optimal value of the corresponding dimension in the evaluated data of product families. $x_{i}$ is the data vector of the product family ' $i$ ' [1]. Therein, $x_{i}(k)$ is analysis indicator $\mathrm{k}$ in product family ' $i$ '.

$$
\left\{\begin{array}{l}
x_{0}=\left\{x_{0}(1), x_{0}(2), \ldots \ldots x_{0}(k), \ldots \ldots x_{0}(n)\right\} \\
x_{1}=\left\{x_{1}(1), x_{1}(2), \ldots \ldots x_{1}(k), \ldots \ldots x_{1}(n)\right\}
\end{array}\right.
$$

The grey relational coefficient can be expressed as follows $[1,76]$ :

$\xi_{i}(k)=\left(\frac{\min _{i} \min _{k}\left|x_{0}(k)-x_{i}(k)\right|+\zeta \max _{i} \max _{k}\left|x_{0}(k)-x_{i}(k)\right|}{\left|x_{0}(k)-x_{i}(k)\right|+\zeta \max _{i} \max _{k}\left|x_{0}(k)-x_{i}(k)\right|}\right)$

Where $\zeta$ is the distinguish coefficient, which is generally $\zeta \epsilon[0,1]$ [78] which is a constant to lower the impact of the extreme value in the calculation [1]. In this study the value of $\zeta$ is $0.5[1,75]$.

The correlation degree matrix is the comparison of the difference between $x_{i}$ and $x_{0}$, and assuming that there are $m$ products, the correlation degree matrix ' $E$ ' is defined as:

$$
E=\left[\begin{array}{cccc}
\varepsilon_{1}(1) & \varepsilon_{1}(2) & \ldots & \varepsilon_{1}(n) \\
\varepsilon_{2}(1) & \varepsilon_{2}(2) & \ldots & \varepsilon_{2}(n) \\
\vdots & \vdots & \ddots & \vdots \\
\varepsilon_{m}(1) & \varepsilon_{m}(2) & \ldots & \varepsilon_{m}(n)
\end{array}\right]
$$

Fuzzy AHP is utilized in this work to determine the criteria weights that helps to make the final best decision. A fuzzy triangular scale is considered where the relative importance values are described. The weights of driving forces in product family evolution are calculated by performing a pairwise comparison with the help of Table III. In this table ' $\alpha$ ' is the fuzzification factor. In general, the ' $\alpha$ ' value ranges between 0 and 1 or it may be any fractional value in between 0 and 1 [79]. Generally, the weights of underlying forces can be calculated with respect to the importance of the highest level (target level). Based on the fuzzy triangular scale, the degree of importance matrix is determined. Table IV shows the importance matrix (partial).

For the calculation of the evaluation result or ranking it is assumed that the weight vector is $W T=\left[w t_{1}, w t_{2}, \ldots, w t_{n}\right]$, the evaluation model of product family based on GRA is established as follows:

$$
R=E \times W T=\left[r_{1}, r_{2}, \ldots . . r_{n}\right]
$$

Thus, Equation (8) shows that with the higher value $r_{i}$, can possibly support the key functional requirements and may imply a greater probability of change or redesign over time. It also shows that with the higher value $r_{i}$, the evaluation of the product is better.

\section{Artificial neural network based forecasting phase}

Forecasting plays an important role in managerial decision making. Using the evaluation data from the previous phases, this section discusses the development of an ANN model to forecast the design specification of some design features of the future product.

An ANN is a modeling and forecasting tool that is prominently used to tackle complex and ill-defined problems. ANN based models are efficient in modeling of complex systems and can be used to simulate the output from a complex set of inputs. Compared with other mathematical models it is time efficient [40]. The advantage of ANN is that without knowing the relationship between the input and output data, the network can be trained to learn that relationship, requiring no previous knowledge of the data characteristics [80]. Therefore, utilization of ANN in a complex system like the product family is worthy/appropriate. In this work, the MATLAB R2018b function 'nntool' [81] is used to design the forecasting model.

Steps regarding building the neural network model are described below:

- Step D.1: Pre-processing the data.

- Step D.2: Tuning parameters. In this step, three different types of network are created. The networks are: Feed Forward-Back Propagation, Layer Recurrent and NARX (Nonlinear Autoregressive Exogenous). The reason afterwards selecting these three networks is that, they have similar combination of parameters. Table $\mathrm{V}$ shows the values of five parameters that are considered for parameter tuning. Please see Table S3 in the supplementary file for the combinations of all five parameters and the mean squared error (MSE) values of 5 runs from 10 runs for each combination. Please see Table S4 in the supplementary file to get the information regarding the combinations of parameters with mean values and standard deviations.

- Step D.3: Selection of the optimal combinations of parameters by the Taguchi method. To calibrate the model, Taguchi's design of experiment (DOE) technique is used to reduce the computational times and required tests for identifying the best possible parameter combination for the ANN model [82]. Here, the orthogonal array L27(35) is employed since there are 5 parameters and each parameter has three levels [82]. Fig 6 and Table VI show the optimal combination of parameters. In our ANN phase, we have used the Hyperbolic tangent sigmoid (TANSIG) function. TANSIG is a Matlab function. The hyperbolic tangent sigmoid transfer function (TANSIG) in the term of neural networks, is related to a bipolar sigmoid that has an output in the range of -1 to +1 . This is mathematically equivalent to $\tanh (\mathrm{N})$ [83].

- Step D.4: Tuning parameters based on the number of layers (hidden) for this optimal model. Table VII provides 
TABLE III: Scaling of Fuzzy AHP

\begin{tabular}{lcccccc}
\hline Categories & \multicolumn{3}{c}{ Triangular Fuzzy AHP } & \multicolumn{3}{c}{ Triangular Fuzzy AHP Reverse } \\
\hline Equally important & 1 & 1 & 1 & 1 & 1 & 1 \\
Weakly important & $3-\alpha$ & 3 & $3+\alpha$ & $\frac{1}{3+\alpha}$ & $\frac{1}{3}$ & $\frac{1}{3-\alpha}$ \\
Fairly important & $5-\alpha$ & 5 & $5+\alpha$ & $\frac{1}{5+\alpha}$ & $\frac{1}{5}$ & $\frac{1}{5-\alpha}$ \\
Strongly important & $7-\alpha$ & 7 & $7+\alpha$ & $\frac{1}{7+\alpha}$ & $\frac{1}{7}$ & $\frac{1}{7-\alpha}$ \\
Absolutely important & $9-\alpha$ & 9 & 9 & $\frac{1}{9}$ & $\frac{1}{9}$ & $\frac{1}{9-\alpha}$ \\
\hline
\end{tabular}

TABLE IV: Fuzzy triangular scale based importance matrix (partial)

\begin{tabular}{|c|c|c|c|c|c|c|}
\hline D.S./D. f. & Display size & Display resolution & Touchscreen size & Touchscreen tech. & Processing speed & Memory capacity \\
\hline Display size & 111 & $1 /(5+\alpha) 1 /(5) 1 /(5-\alpha)$ & 111 & $1 /(7-\alpha) 1 /(7) 1 /(7+\alpha)$ & $1 /(5+\alpha) 1 /(5) 1 /(5-\alpha)$ & $1 /(3+\alpha) 1 /(3) 1 /(3-\alpha)$ \\
\hline Display resolution & $5-\alpha 55+\alpha$ & 111 & $5-\alpha 55+\alpha$ & $3-\alpha 33+\alpha$ & $3-\alpha 33+\alpha$ & $3-\alpha 33+\alpha$ \\
\hline Touchscreen size & 111 & $1 /(5+\alpha) 1 /(5) 1 /(5-\alpha)$ & 111 & $1 /(5+\alpha) 1 /(5) 1 /(5-\alpha)$ & $1 /(5+\alpha) 1 /(5) 1 /(5-\alpha)$ & $1 /(3+\alpha) 1 /(3) 1 /(3-\alpha)$ \\
\hline Touchscreen technology & 7- $\alpha 77+\alpha$ & $1 /(3+\alpha) 1 /(3) 1 /(3-\alpha)$ & $5-\alpha 55+\alpha$ & 111 & $1 /(3+\alpha) 1 /(3) 1 /(3-\alpha)$ & $3-\alpha 33+\alpha$ \\
\hline Sound quality & $1 /(7-\alpha) 1 /(7) 1 /(7+\alpha)$ & $1 /(7-\alpha) 1 /(7) 1 /(7+\alpha)$ & $1 /(7-\alpha) 1 /(7) 1 /(7+\alpha)$ & $1 /(5+\alpha) 1 /(5) 1 /(5-\alpha)$ & $1 /(7-\alpha) 1 /(7) 1 /(7+\alpha)$ & $1 /(5+\alpha) 1 /(5) 1 /(5-\alpha)$ \\
\hline Processing speed & $5-\alpha 55+\alpha$ & $1 /(3+\alpha) 1 /(3) 1 /(3-\alpha)$ & $5-\alpha 55+\alpha$ & $3-\alpha 33+\alpha$ & 111 & $3-\alpha 33+\alpha$ \\
\hline Memory capacity & $3-\alpha 33+\alpha$ & $1 /(3+\alpha) 1 /(3) 1 /(3-\alpha)$ & $3-\alpha 33+\alpha$ & $1 /(3+\alpha) 1 /(3) 1 /(3-\alpha)$ & $1 /(3+\alpha) 1 /(3) 1 /(3-\alpha)$ & 111 \\
\hline Data transfer & $3-\alpha 33+\alpha$ & $1 /(3+\alpha) 1 /(3) 1 /(3-\alpha)$ & $3-\alpha 33+\alpha$ & $1 /(3+\alpha) 1 /(3) 1 /(3-\alpha)$ & $1 /(5+\alpha) 1 /(5) 1 /(5-\alpha)$ & $1 /(3+\alpha) 1 /(3) 1 /(3-\alpha)$ \\
\hline Internet \&connectivity speed & $3-\alpha 33+\alpha$ & $1 /(5+\alpha) 1 /(5) 1 /(5-\alpha)$ & $3-\alpha 33+\alpha$ & $1 /(3+\alpha) 1 /(3) 1 /(3-\alpha)$ & $1 /(3+\alpha) 1 /(3) 1 /(3-\alpha)$ & $1 /(5+\alpha) 1 /(5) \quad 1 /(5-a)$ \\
\hline Operating system & $3-\alpha 33+\alpha$ & $1 /(3+\alpha) 1 /(3) 1 /(3-\alpha)$ & $3-\alpha 33+\alpha$ & $1 /(3+\alpha) 1 /(3) 1 /(3-\alpha)$ & $1 /(3+\alpha) 1 /(3) 1 /(3-\alpha)$ & $1 /(3+\alpha) 1 /(3) 1 /(3-\alpha)$ \\
\hline Chipset technology & $3-\alpha 33+\alpha$ & $1 /(3+\alpha) 1 /(3) 1 /(3-\alpha)$ & $3-\alpha 33+\alpha$ & $1 /(3+\alpha) 1 /(3) 1 /(3-\alpha)$ & $1 /(5+\alpha) 1 /(5) 1 /(5-\alpha)$ & $1 /(5+\alpha) 1 /(5) 1 /(5-\alpha)$ \\
\hline Baseband memory & $5-\alpha 55+\alpha$ & $1 /(3+\alpha) 1 /(3) 1 /(3-\alpha)$ & $5-\alpha 55+\alpha$ & $1 /(3+\alpha) 1 /(3) 1 /(3-\alpha)$ & $1 /(5+\alpha) 1 /(5) 1 /(5-\alpha)$ & $1 /(3+\alpha) 1 /(3) 1 /(3-\alpha)$ \\
\hline Battery Performance & $5-\alpha 55+\alpha$ & $1 /(3+\alpha) 1 /(3) 1 /(3-\alpha)$ & $5-\alpha 55+\alpha$ & $1 /(3+\alpha) 1 /(3) 1 /(3-\alpha)$ & $1 /(3+\alpha) 1 /(3) 1 /(3-\alpha)$ & $1 /(5+\alpha) 1 /(5) 1 /(5-\alpha)$ \\
\hline GPS & $7-\alpha 77+\alpha$ & $1 /(7-\alpha) 1 /(7) 1 /(7+\alpha)$ & $7-\alpha 77+\alpha$ & $1 /(7-\alpha) 1 /(7) 1 /(7+\alpha)$ & $1 /(7-\alpha) 1 /(7) 1 /(7+\alpha)$ & $1 /(7-\alpha) 1 /(7) 1 /(7+\alpha)$ \\
\hline Camera resolution & $7-\alpha 77+\alpha$ & $1 /(3+\alpha) 1 /(3) 1 /(3-\alpha)$ & 7- $\alpha 77+\alpha$ & $1 /(5+\alpha) 1 /(5) 1 /(5-\alpha)$ & $1 /(5+\alpha) 1 /(5) 1 /(5-\alpha)$ & $1 /(7-\alpha) 1 /(7) 1 /(7+\alpha)$ \\
\hline Video capability & $1 /(5+\alpha) 1 /(5) 1 /(5-\alpha)$ & $1 /(7-\alpha) 1 /(7) 1 /(7+\alpha)$ & $1 /(5+\alpha) 1 /(5) 1 /(5-\alpha)$ & $1 /(7-\alpha) 1 /(7) 1 /(7+\alpha)$ & $1 /(9) 1 /(9) 1 /(9-\alpha)$ & $1 /(7-\alpha) 1 /(7) 1 /(7+\alpha)$ \\
\hline Casing /weight & $1 /(5+\alpha) 1 /(5) 1 /(5-\alpha)$ & $1 /(9) 1 /(9) 1 /(9-\alpha)$ & $1 /(5+\alpha) 1 /(5) 1 /(5-\alpha)$ & $1 /(7-\alpha) 1 /(7) 1 /(7+\alpha)$ & $1 /(7-\alpha) 1 /(7) 1 /(7+\alpha)$ & $1 /(9) 1 /(9) 1 /(9-\alpha)$ \\
\hline Protection & $1 /(3+\alpha) 1 /(3) 1 /(3-\alpha)$ & $1 /(7-\alpha) 1 /(7) 1 /(7+\alpha)$ & $1 /(3+\alpha) 1 /(3) 1 /(3-\alpha)$ & $1 /(5+\alpha) 1 /(5) 1 /(5-\alpha)$ & $1 /(7-\alpha) 1 /(7) 1 /(7+\alpha)$ & $1 /(7-\alpha) 1 /(7) 1 /(7+\alpha)$ \\
\hline Price & $3-\alpha 33+\alpha$ & $1 /(3+\alpha) 1 /(3) 1 /(3-\alpha)$ & $3-\alpha 33+\alpha$ & $1 /(3+\alpha) 1 /(3) 1 /(3-\alpha)$ & $1 /(5+\alpha) 1 /(5) 1 /(5-\alpha)$ & $1 /(5+\alpha) 1 /(5) 1 /(5-\alpha)$ \\
\hline Ease of use & $1 /(7-\alpha) 1 /(7) 1 /(7+\alpha)$ & $1 /(5+\alpha) 1 /(5) 1 /(5-\alpha)$ & $1 /(7-\alpha) 1 /(7) 1 /(7+\alpha)$ & $1 /(7-\alpha) 1 /(7) 1 /(7+\alpha)$ & $1 /(3+\alpha) 1 /(3) 1 /(3-\alpha)$ & $1 /(9) 1 /(9) 1 /(9-\alpha)$ \\
\hline Size & $1 /(3+\alpha) 1 /(3) 1 /(3-\alpha)$ & $1 /(7-\alpha) 1 /(7) 1 /(7+\alpha)$ & $1 /(3+\alpha) 1 /(3) 1 /(3-\alpha)$ & $1 /(5+\alpha) 1 /(5) 1 /(5-\alpha)$ & $1 /(7-\alpha) 1 /(7) 1 /(7+\alpha)$ & $1 /(7-\alpha) 1 /(7) 1 /(7+\alpha)$ \\
\hline Sensors & $5-\alpha 55+\alpha$ & $1 /(5+\alpha) 1 /(5) 1 /(5-\alpha)$ & $5-\alpha 55+\alpha$ & $1 /(3+\alpha) 1 /(3) 1 /(3-\alpha)$ & $1 /(7-\alpha) 1 /(7) 1 /(7+\alpha)$ & $1 /(5+\alpha) 1 /(5) 1 /(5-\alpha)$ \\
\hline Impact on environments & $1 /(3+\alpha) 1 /(3) 1 /(3-\alpha)$ & $1 /(5+\alpha) 1 /(5) 1 /(5-\alpha)$ & $1 /(3+\alpha) 1 /(3) 1 /(3-\alpha)$ & $1 /(5+\alpha) 1 /(5) 1 /(5-\alpha)$ & $1 /(5+\alpha) 1 /(5) 1 /(5-\alpha)$ & $1 /(5+\alpha) 1 /(5) 1 /(5-\alpha)$ \\
\hline Number of SIM cards & $1 /(5+\alpha) 1 /(5) 1 /(5-\alpha)$ & $1 /(9) 1 /(9) 1 /(9-\alpha)$ & $1 /(5+\alpha) 1 /(5) 1 /(5-\alpha)$ & $1 /(9) 1 /(9) 1 /(9-\alpha)$ & $1 /(9) 1 /(9) 1 /(9-\alpha)$ & $1 /(7-\alpha) 1 /(7) 1 /(7+\alpha)$ \\
\hline Mobile phone safety & $1 /(3+\alpha) 1 /(3) 1 /(3-\alpha)$ & $1 /(9) 1 /(9) 1 /(9-\alpha)$ & $1 /(3+\alpha) 1 /(3) 1 /(3-\alpha)$ & $1 /(5+\alpha) 1 /(5) 1 /(5-\alpha)$ & $1 /(7-\alpha) 1 /(7) 1 /(7+\alpha)$ & $1 /(7-\alpha) 1 /(7) 1 /(7+\alpha)$ \\
\hline Application/Apps & $1 /(3+\alpha) 1 /(3) 1 /(3-\alpha)$ & $1 /(5+\alpha) 1 /(5) 1 /(5-\alpha)$ & $1 /(3+\alpha) 1 /(3) 1 /(3-\alpha)$ & $1 /(7-\alpha) 1 /(7) 1 /(7+\alpha)$ & $1 /(5+\alpha) 1 /(5) 1 /(5-\alpha)$ & $1 /(3+\alpha) 1 /(3) 1 /(3-\alpha)$ \\
\hline Network & $5-\alpha 55+\alpha$ & $1 /(3+\alpha) 1 /(3) 1 /(3-\alpha)$ & $5-\alpha 55+\alpha$ & $3-\alpha 33+\alpha$ & $1 /(5+\alpha) 1 /(5) 1 /(5-\alpha)$ & $3-\alpha 33+\alpha$ \\
\hline Robustness & $1 /(3+\alpha) 1 /(3) 1 /(3-\alpha)$ & $1 /(7-\alpha) 1 /(7) 1 /(7+\alpha)$ & $1 /(3+\alpha) 1 /(3) 1 /(3-\alpha)$ & $1 /(3+\alpha) 1 /(3) 1 /(3-\alpha)$ & $1 /(9) 1 /(9) 1 /(9-\alpha)$ & $1 /(7-\alpha) 1 /(7) 1 /(7+\alpha)$ \\
\hline Build/material & $1 /(7-\alpha) 1 /(7) 1 /(7+\alpha)$ & $1 /(9) 1 /(9) 1 /(9-\alpha)$ & $1 /(7-\alpha) 1 /(7) 1 /(7+\alpha)$ & $1 /(5+\alpha) 1 /(5) 1 /(5-\alpha)$ & $1 /(9) 1 /(9) 1 /(9-\alpha)$ & $1 /(9) 1 /(9) 1 /(9-\alpha)$ \\
\hline
\end{tabular}

the MSE values of 10 runs for different numbers of layers. From this table it is found that the average value of MSE for ' 4 ' layers are minimum. Therefore, it is considered that the performance of the ANN model with four hidden layers is better then other numbers of layers.

- Step D.5: Development of the neural network model based on the aforementioned steps for forecasting.

- Step D.6: Forecasting based on the optimal model.

In this paper, the network is a multi-input multi output system. The training model contains 22 input variables in the input layer, four hidden layers all including 10 neurons and 6 outputs in the output layer.

\section{SEnsitivity AnAlysis}

The main objective of sensitivity analysis is to verify the consistency of the model behaviour [84]. How the change of values in the output of a model can be attributed by changing its input factors can be investigated by sensitivity analysis [85]. Sensitivity analysis is also used to assess the robustness of a model's outcome $[86,87]$. The output of the model is said to be sensitive if the output varies remarkably by varying the input variable. On the other hand, the output of the model is said to be insensitive or robust if the output does not change significantly [86]. Robustness helps strengthen the reliability of the model [86].

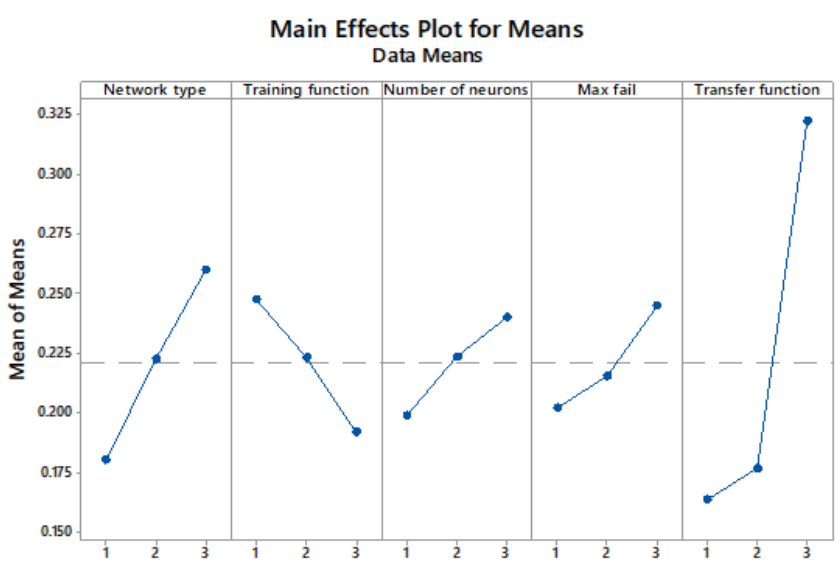

Fig. 6: Optimal combinations of parameters by Taguchi method

There are different types of sensitivity analysis, such as: (i) Quantitative and Qualitative SA, (ii) Local and Global SA, (iii) One-At-a-Time (OAT) and All-At-a-Time (AAT) etc. [85]. The distinction between OAT and AAT methods is based on the approach adopted to select input samples [85]. Specifically:

- In OAT methods, one input factor is changed at a time, 
TABLE V: Values of different parameters

\begin{tabular}{lllll}
\hline Number & Parameter & Level 1 & Level 2 & Level 3 \\
\hline 1 & Network type & FF-BP & Layer Recurrent & NARX \\
2 & Training function & TRAINLM & TRAINSCG & TRAINGDX \\
3 & Number of neurons & 10 & 20 & 30 \\
4 & Maximum fail & 50 & 100 & 200 \\
5 & Transfer function & TANSIG & LOGSIG & PURELIN \\
\hline
\end{tabular}

TABLE VI: Optimal combination of parameters

\begin{tabular}{cll}
\hline Number & Parameter type & Selected parameter \\
\hline 1 & & \\
2 & Network type & FF-BP \\
3 & Training function & TRAINGDX \\
4 & Number of neurons & 10 \\
5 & Maximum fail & 50 \\
\end{tabular}

TABLE VII: MSE values for different number of hidden layers

\begin{tabular}{|c|c|c|c|c|c|c|c|c|c|c|c|}
\hline $\begin{array}{l}\text { No. of } \\
\text { layers }\end{array}$ & Run1 & Run2 & Run3 & Run4 & Run5 & Run6 & Run7 & Run8 & Run9 & Run10 & Average \\
\hline 1 & 0.0397 & 0.0947 & 0.1799 & 0.0578 & 0.3149 & 0.0959 & 0.0324 & 0.0458 & 0.0162 & 0.0823 & 0.09596 \\
\hline 2 & 0.0672 & 0.0342 & 0.2171 & 0.0085 & 0.0218 & 0.0368 & 0.0961 & 0.0456 & 0.0424 & 0.0206 & 0.05903 \\
\hline 3 & 0.045 & 0.0664 & 0.0073 & 0.1078 & 0.036 & 0.1829 & 0.0555 & 0.0372 & 0.0365 & 0.0589 & 0.06335 \\
\hline 4 & 0.0315 & 0.0511 & 0.0576 & 0.0145 & 0.0102 & 0.0774 & 0.0798 & 0.0522 & 0.0758 & 0.0114 & 0.04615 \\
\hline 5 & 0.2409 & 0.0619 & 0.0859 & 0.0263 & 0.1099 & 0.048 & 0.0175 & 0.0365 & 0.2213 & 0.0569 & 0.09051 \\
\hline
\end{tabular}

by keeping all other factor fixed and check the impact on output variations.

- In AAT methods, output variations are induced by varying all the input factors simultaneously.

In our paper, we consider different scenarios by using OAT and AAT sensitivity analysis methods. The sensitivity analysis has been done to check the robustness of the evolution model (Evaluation phase). Hou et al. [1] also determined the sensitivity of influencing factors in the process of product family evolution. The sensitivity analysis (scenario analysis) is done in our study to verify the robustness of the evaluation model. In the evaluation phase, the construction of the relationship matrix is judgmental as well as in Fuzzy AHP, the determination of the degree of importance is also judgmental. Hence, in this paper sensitivity analysis is done by considering different scenarios by selecting the features randomly.

In this work, sensitivity analysis is done at several stages of the evaluation phase:

- Sensitivity analysis by varying the relationship matrix during the evaluation of design features.

- Sensitivity analysis by varying the fuzzification factor for both design features evaluation and product evaluation.

- Sensitivity analysis by varying the importance matrix of fuzzy AHP for both design features evaluation and product evaluation.

- Sensitivity analysis by varying the importance matrix of fuzzy AHP for product evaluation.

A. Sensitivity analysis by varying the relationship matrix during the evaluation of design features

Relationship matrix between product design specifications (PDS) and design features is the first step of the evaluation of design features at evaluation phase. This matrix is constructed based on the experience and knowledge of the designer. In this case, seven scenarios are considered for sensitivity analysis. Scenario 4 to scenario 7 are chosen randomly. The scenarios are:

- Scenario 1: In this scenario, all the input values are varied at a time in an optimistic way.

- Scenario 2: In this scenario, all the input values varied at a time in a neutral way.

- Scenario 3: In this scenario, all the input values varied at a time in a pessimistic way.

- Scenario 4: In this scenario, the input values of camera feature has been changed.

- Scenario 5: In this scenario, the input values of software feature has been changed.

- Scenario 6: In this scenario, the input values of processor feature has been changed.

- Scenario 7: In this scenario, the input values of sound feature and screen protector feature has been changed.

The results of grey relational grade and rank of each feature for different scenarios are summarized in Table A.3 in the Appendix and the perceptual map representation of these results are in Fig. 7.

The perceptual map in Fig. 7 shows the relative positions or the ranking positions of the sixteen design features. The perceptual map is developed using MDS map [88]. In this map, by visual inspection, all features are divided into three clusters. The ranking position of the features in Scenario 2 and Scenario 6 is a little bit different then the ranking of features in other scenarios. From Fig. 7 it is found that the positions of F3 (Software), F1 (Processor) are relatively closer to the scenarios and they are the most influential features. In the cluster, F8F16 features F14 (GPS), F15 (Sound system) and F16 (Screen protector) respectively are far away from all of the scenarios and shows the lowest-ranking positions respectively in the 


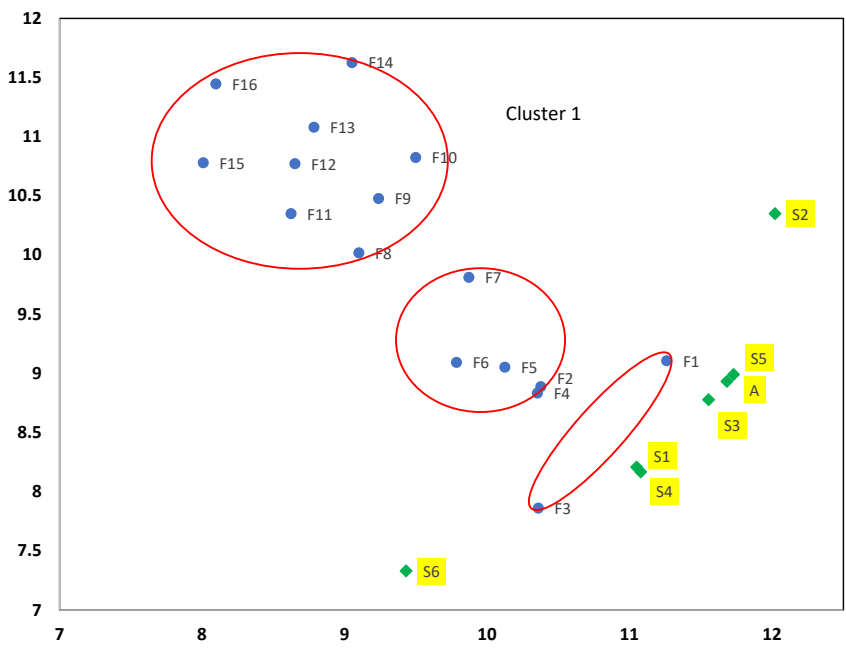

Fig. 7: Perceptual map of Table A.3

map. The cluster that contains features F2-F7 is positioned at the mid of the map and represents the mid-ranked features.

B. Sensitivity analysis by varying the fuzzification factor for both design features evaluation and product evaluation

This sensitivity analysis was conducted by varying the fuzzification factor $(\alpha)$ in the fuzzy triangular scale. The model output is analysed for six different values of the fuzzification factor $(\alpha)$ and the values are; $\alpha=0,0.2,0.4,0.6,0.8$ and 1 . The sensitivity of the ranking is analysed and the results indicate that the ranking is not altered by changing the fuzzification factor. Therefore, for any value of $\alpha$ the evaluation of design features and the evaluation of products are the same.

C. Sensitivity analysis by varying the importance matrix of fuzzy AHP for design feature evaluation

This sensitivity analysis is performed to investigate the impact of change or variation in the importance matrix of Fuzzy AHP to the output of the design features evaluation (ranking). In this case, five random scenarios are considered. The scenarios are:

- Scenario 1: In this scenario, only the importance level of display size has been changed.

- Scenario 2: In this scenario, the importance level of display size, operating system, and chipset have been changed.

- Scenario 3: In this scenario, the importance level of display size, operating system, chipset and processing speed have been changed.

- Scenario 4: In this scenario, the importance level of display size, operating system, chipset, processing speed, data transfer and network have been changed.

- Scenario 5: In this scenario, the importance level of display size, operating system, chipset, processing speed, data transfer network and Sound quality have been changed.

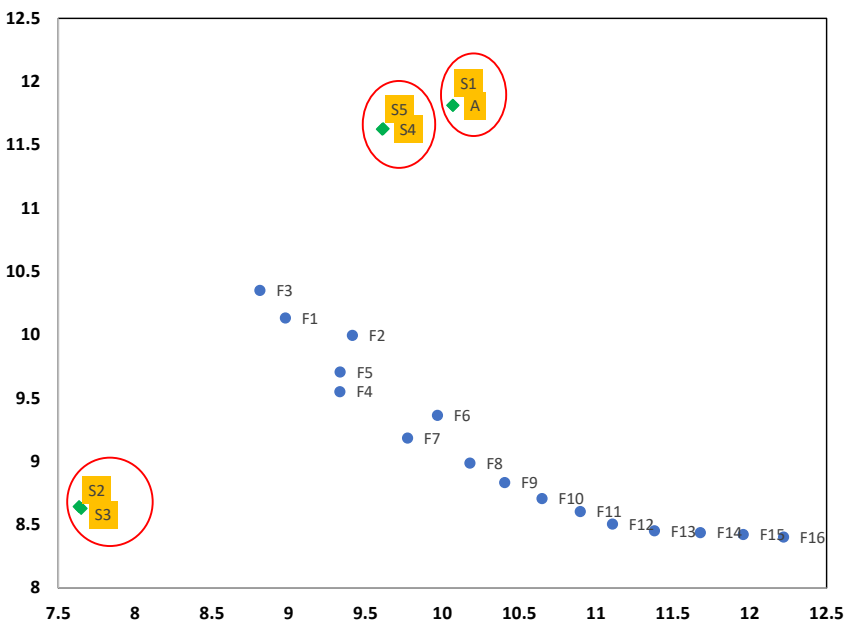

Fig. 8: Perceptual map of Table A.4

The results of grey relational grade and rank of each feature for different scenarios are summarized in Table A.4 in the Appendix and the perceptual map representation of these results are in Fig. 8.

The perceptual map in Fig. 8 shows the relative positions or the ranking positions of the sixteen design features after varying the importance matrix for design features evaluation. In this map, by visual inspection, the scenarios are divided into three clusters. The first cluster contains Actual (A) and Scenario 1 (S1) where in Scenario 1 we have changed the importance level of only one feature; namely, Display size. In the second cluster including scenarios S2 and S3, the number of design features that have changed is almost the same, 3 and 4 respectively. Same as the second cluster, in cluster three S4-S5 the number of design features that have changed is almost the same, 6 and 7 respectively. From Fig. 8 it is found that the position of F3 (Software), F1 (Processor) and F2 (Touchscreen) are closer to the scenarios and are the most influential features respectively. F4-F7 are positioned at the mid of the map and represent the mid-ranked features whereas F8-F16, features are far away from all of the scenarios and show the lowest ranking positioned features in the map.

D. Sensitivity analysis by varying the importance matrix of fuzzy AHP for product evaluation

This sensitivity analysis is performed to investigate the impact of variation in the importance matrix of fuzzy AHP to the output of the product evaluation (ranking). In this case, five random scenarios are considered:

- Scenario 1: In this scenario, only the importance level of processor has been changed.

- Scenario 2: In this scenario, the importance level of processor, operating system, and chipset has been changed.

- Scenario 3: In this scenario, the importance level of processor, operating system, chipset and price has been changed.

- Scenario 4: In this scenario, the importance level of processor, operating system, chipset, price and network has been changed. 
TABLE VIII: The results of grey relational grade and rank of each product

\begin{tabular}{|c|c|c|c|c|c|c|c|c|}
\hline $\begin{array}{c}\text { Product } \\
\text { No. }\end{array}$ & $\begin{array}{l}\text { Product } \\
\text { name }\end{array}$ & Grade/Rank & Actual & Scenario 1 & Scenario 2 & Scenario 3 & Scenario 4 & Scenario 5 \\
\hline \multirow[t]{2}{*}{$\mathrm{P} 1$} & \multirow{2}{*}{ iPhone } & Grade & 0.57544 & 0.576063 & 0.577974 & 0.579678 & 0.58226 & 0.58286 \\
\hline & & Rank & 25 & 25 & 25 & 25 & 25 & 25 \\
\hline \multirow[t]{2}{*}{$\mathrm{P} 2$} & \multirow{2}{*}{ iPhone 3G } & Grade & 0.59131 & 0.592479 & 0.594374 & 0.597001 & 0.60122 & 0.60271 \\
\hline & & Rank & 24 & 24 & 24 & 24 & 24 & 24 \\
\hline \multirow[t]{2}{*}{ P3 } & \multirow{2}{*}{ iPhone 3GS } & Grade & 0.60860 & 0.610159 & 0.611947 & 0.614498 & 0.62061 & 0.62220 \\
\hline & & Rank & 23 & 23 & 23 & 23 & 23 & 23 \\
\hline \multirow[t]{2}{*}{$\mathrm{P} 4$} & \multirow{2}{*}{ iPhone 4} & Grade & 0.63228 & 0.633868 & 0.637289 & 0.639311 & 0.64478 & 0.64607 \\
\hline & & Rank & 22 & 22 & 22 & 22 & 22 & 22 \\
\hline \multirow[t]{2}{*}{ P5 } & \multirow{2}{*}{ iPhone 4S } & Grade & 0.64652 & 0.647955 & 0.651716 & 0.654231 & 0.65951 & 0.66058 \\
\hline & & Rank & 21 & 21 & 21 & 21 & 21 & 21 \\
\hline \multirow[t]{2}{*}{ P6 } & \multirow{2}{*}{ iPhone 5} & Grade & 0.67265 & 0.67459 & 0.678159 & 0.680511 & 0.68805 & 0.68919 \\
\hline & & Rank & 19 & 19 & 19 & 19 & 19 & 19 \\
\hline \multirow[t]{2}{*}{$\mathrm{P} 7$} & \multirow{2}{*}{ iPhone 5C } & Grade & 0.66883 & 0.670821 & 0.675429 & 0.678046 & 0.68589 & 0.68777 \\
\hline & & Rank & 18 & 18 & 18 & 18 & 18 & 18 \\
\hline \multirow[t]{2}{*}{ P8 } & \multirow{2}{*}{ iPhone 5S } & Grade & 0.68227 & 0.68397 & 0.688594 & 0.690939 & 0.69844 & 0.70013 \\
\hline & & Rank & 18 & 18 & 18 & 18 & 18 & 18 \\
\hline \multirow[t]{2}{*}{ P9 } & \multirow{2}{*}{ iPhone 6} & Grade & 0.730529 & 0.751252 & 0.579941 & 0.730551 & 0.730466 & 0.73053 \\
\hline & & Rank & 17 & 17 & 17 & 17 & 17 & 17 \\
\hline \multirow[t]{2}{*}{ P10 } & jPhone 6 Plus & Grade & 0.74167 & 0.744129 & 0.750063 & 0.754061 & 0.75877 & 0.75954 \\
\hline & 1Phone 6 Plus & Rank & 14 & 14 & 14 & 14 & 14 & 14 \\
\hline P11 & & Grade & 0.73344 & 0.734689 & 0.738962 & 0.74189 & 0.74809 & 0.74995 \\
\hline & 1Phone 6S & Rank & 15 & 15 & 15 & 15 & 15 & 15 \\
\hline P12 & iPhone $6 \mathrm{~s}$ & Grade & 0.76107 & 0.76311 & 0.768304 & 0.772114 & 0.77642 & 0.77629 \\
\hline & Plus & Rank & 12 & 12 & 12 & 12 & 12 & 12 \\
\hline P13 & & Grade & 0.71528 & 0.716135 & 0.720108 & 0.720223 & 0.72705 & 0.72974 \\
\hline & iPhone SE & Rank & 16 & 16 & 16 & 16 & 16 & 16 \\
\hline P14 & & Grade & 0.75586 & 0.756634 & 0.760028 & 0.760541 & 0.76633 & 0.76717 \\
\hline & iPhone 7 & Rank & 13 & 13 & 13 & 13 & 13 & 13 \\
\hline $\mathrm{P} 15$ & & Grade & 0.79693 & 0.798497 & 0.803015 & 0.804409 & 0.80816 & 0.80942 \\
\hline & iPhone 7 Plus & Rank & 10 & 10 & 10 & 10 & 10 & 10 \\
\hline P16 & & Grade & 0.78783 & 0.788312 & 0.789658 & 0.789385 & 0.79382 & 0.79404 \\
\hline & iPhone 8 & Rank & 11 & 11 & 11 & 11 & 11 & 11 \\
\hline P16 & & Grade & 0.83319 & 0.834296 & 0.835266 & 0.835305 & 0.83754 & 0.83732 \\
\hline & 1Phone 8 Plus & Rank & 8 & 8 & 8 & 8 & 8 & 8 \\
\hline P16 & & Grade & 0.86859 & 0.869579 & 0.871612 & 0.873971 & 0.87553 & 0.87436 \\
\hline & iPhone X & Rank & 6 & 6 & 6 & 6 & 6 & 6 \\
\hline P16 & & Grade & 0.86013 & 0.859547 & 0.861425 & 0.859545 & 0.86404 & 0.86407 \\
\hline & iPhone XR & Rank & 7 & 7 & 7 & 7 & 7 & 7 \\
\hline P16 & & Grade & 0.91514 & 0.915549 & 0.913371 & 0.91346 & 0.91313 & 0.91066 \\
\hline & iPhone XS & Rank & 4 & 4 & 4 & 4 & 4 & 4 \\
\hline P16 & iPhone XS & Grade & 0.94539 & 0.946431 & 0.944708 & 0.946644 & 0.94496 & 0.94170 \\
\hline & Max & Rank & 3 & 3 & 3 & 3 & 3 & 3 \\
\hline P16 & & Grade & 0.88239 & 0.881036 & 0.882615 & 0.879575 & 0.8838 & 0.88355 \\
\hline & iPhone 11 & Rank & 5 & 5 & 5 & 5 & 5 & 5 \\
\hline P16 & & Grade & 0.96130 & 0.960707 & 0.960513 & 0.958689 & 0.96016 & 0.95872 \\
\hline & iPhone 11 Pro & Rank & 2 & 2 & 2 & 2 & 2 & 2 \\
\hline P16 & iPhone 11 Pro & Grade & 0.99772 & 0.99772 & 0.997727 & 0.997706 & 0.99769 & 0.99769 \\
\hline & $\operatorname{Max}$ & Rank & 1 & 1 & 1 & 1 & 1 & 1 \\
\hline P16 & iPhone SE & Grade & 0.81837 & 0.816937 & 0.819292 & 0.815899 & 0.820100 .81989 & \\
\hline & ( $2^{n d}$ Gen.) & Rank & 9 & 9 & 9 & 9 & 9 & 9 \\
\hline
\end{tabular}

- Scenario 5: In this scenario, the importance level of processor, operating system, chipset, price, network, battery power and battery life has been changed.

The results of grey relational grade and rank of each product for different scenarios are summarized in Table VIII. From the table it can be seen that there is no change in the rank of the products.

From the above sensitivity analysis, it is clear that the proposed model is robust and can reliably contribute to decisionmaking.

\section{RESUlTS AND Discussions}

The details about the data, such as the source, size, period and types are provided in the data repository and the supplementary file. Dataset Link: Dynamic Modelling for Product Family Evolution Combined with Artificial Neural Network Based Forecasting Model

Before the application of the dynamic model an analysis has been done on the data and features for different iPhone products. Fig. B.1 to Fig. B.5 in the Appendix shows the analysis.

\section{A. Evaluation of product family evolution}

From GRA analysis the evaluation result of product family evolution is generated. After calculating Equation (8); the result of the evaluation vector for design features, $R_{d f}$ is: Software $>$ Processor $>$ Touchscreen $>$ Outer casing $>$ Data transfer $>$ Physical interface $>$ Internet and connectivity $>$ GPU $>$ Display $>$ Flash memory $>$ DRAM memory $>$ Battery $>$ Camera $>$ GPS $>$ Sound system $>$ Screen protector. The result of the ranking is shown in Table IX. From this result, it is found that design features such as "Software", "Processor", "Touchscreen" are more likely to require ongoing modifications and variations and have a great impact on future product development.

Similarly, from Equation (8) the result in the evaluation vector for products, $R_{p}$ is given in the Table $\mathrm{X}$. The first five products in Apple's iPhone product family evaluation are: 
TABLE IX: Ranking of iPhone products

\begin{tabular}{cc}
\hline Product name & Rank \\
\hline iPhone 11 Pro Max & 1 \\
iPhone 11 Pro & 2 \\
iPhone XS Max & 3 \\
iPhone XS & 4 \\
iPhone 11 & 5 \\
iPhone X & 6 \\
iPhone XR & 7 \\
iPhone 8 Plus & 8 \\
iPhone SE (2nd Gen.) & 9 \\
iPhone 7 Plus & 10 \\
iPhone 8 & 11 \\
iPhone 6s Plus & 12 \\
iPhone 7 & 13 \\
iPhone 6 Plus & 14 \\
iPhone 6s & 15 \\
iPhone SE & 16 \\
iPhone 6 & 17 \\
iPhone 5s & 18 \\
iPhone 5 & 19 \\
iPhone 5C & 20 \\
iPhone 4S & 21 \\
iPhone 4 & 22 \\
iPhone 3GS & 23 \\
iPhone 3G & 24 \\
iPhone & 25 \\
\hline
\end{tabular}

TABLE X: Ranking of design features

\begin{tabular}{cc}
\hline Design features & Rank \\
\hline Software & 1 \\
Processor/CPU & 2 \\
Touchscreen & 3 \\
Outer casing & 4 \\
Data transfer & 5 \\
Physical interfaces & 6 \\
Internet and connectivity & 7 \\
GPU & 8 \\
Display & 9 \\
Flash memory & 10 \\
DRAM memory & 11 \\
Battery & 12 \\
Camera & 13 \\
GPS & 14 \\
Screen protector & 15 \\
Sound & 16 \\
\hline
\end{tabular}

iPhone 11 Pro Max > iPhone 11 Pro >iPhone XS Max > iPhone XS $>$ iPhone 11. The iPhone 11 Pro Max performs better than any other iPhone's product. The performance of iPhone 11 Pro Max and iPhone 11 Pro is better than iPhone XS Max and iPhone XS. However, the performance of iPhone 11 is lower than iPhone XS Max and iPhone XS. From Table X it is also found that the performance rank of the latest iPhone SE (2nd Gen.) is "9". Its performance level is lower than iPhone 8 Plus; a product that was released three years ago, whereas the rank of iPhone SE (1st Gen.) is 16.

\section{B. Simulation results for forecasting model}

In this forecasting phase, an ANN-based forecasting model is used to forecast the design specification of some of the influential design features. To forecast the features of the future product, data for the first 15 products from the product evaluation are considered in this forecasting model. Moreover, four features-software (operating system and chipset), processor, touchscreen (touchscreen size and technology), and data transfer (network)-from the feature's evaluation are measured for forecasting. Table XI and Table XII shows the list of input
TABLE XI: List of input variables

\begin{tabular}{cc}
\hline Number & Input variables \\
\hline 1 & Display size \\
2 & Display resolution (vertical) \\
3 & Display resolution (horizontal) \\
4 & DRAM memory \\
5 & Flash memory (max) \\
6 & Flash memory (min) \\
7 & Internet and connectivity \\
8 & Bluetooth \\
9 & Battery capacity \\
10 & Battery life \\
11 & GPS \\
12 & Camera resolution \\
13 & Number of camera \\
14 & Front camera resolution \\
15 & Video capacity \\
16 & Dimension (Height) \\
17 & Dimension (Width) \\
18 & Dimension (Depth) \\
19 & Sensors \\
20 & Casing (weight) \\
21 & Price (max) \\
22 & Price (min) \\
\hline
\end{tabular}

TABLE XII: List of output variables

\begin{tabular}{cc}
\hline Number & Output variables \\
\hline 1 & Operating system \\
2 & Chipset \\
3 & Processor \\
4 & Touchscreen size \\
5 & Touchscreen technology \\
6 & Network $(\mathrm{G})$ \\
\hline
\end{tabular}

and output variables respectively. The data structure of the training data are provided in the data repository.

From 25 datasets, 15 sets of data points are selected for training and 5 sets are used as a sample to validate the ANN model. The 15 sets of data are divided into 3 groups; $70 \%$ is used for training, $15 \%$ is used for testing and $15 \%$ used for validation. The model with the optimal combination of parameters is used to design the forecasting model. [89] and [90] selected as the training algorithm due to achieving low error rates in their ANN models with smaller data sets. In our proposed model TRAINGDX is selected as the learning algorithm [91]. Fig. 9 shows the MSE progress.

TABLE XIII: Performance result

\begin{tabular}{lcc}
\hline Model & RMSE & $R^{2}$ \\
\hline ANN & 0.1268 & 0.98863 \\
SVR & 0.6569 & 0.7820 \\
\hline
\end{tabular}

Fig. 10 to Fig. 15 show the predicted outputs and the target data used for training. The performance of the forecasting can be evaluated by Root Mean Squared Error (RMSE) that provides the difference between the actual outputs and the predicted outputs from the network. The formula for computing RMSE is as follows:

$$
R M S E=\sqrt{\frac{1}{N_{o}} \sum_{i=1}^{N_{o}}\left(A_{i}-P_{i}\right)^{2}}
$$

Where ' $N_{o}$ ' is the total number of observations, $A_{i}$ is the actual value and $P_{i}$ is the predicted value.

In this case, the RMSE value is 0.1268 , and the coefficient of determination $\left(R^{2}\right)$ value is 0.98863 . This $R^{2}$ value 


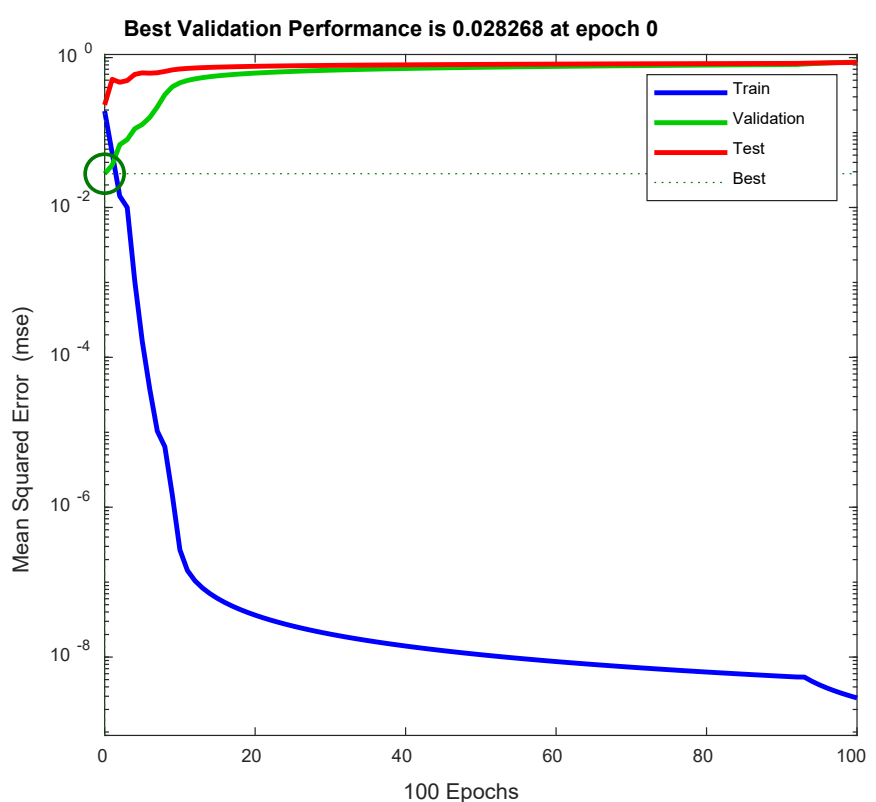

Fig. 9: MSE vs. iterations

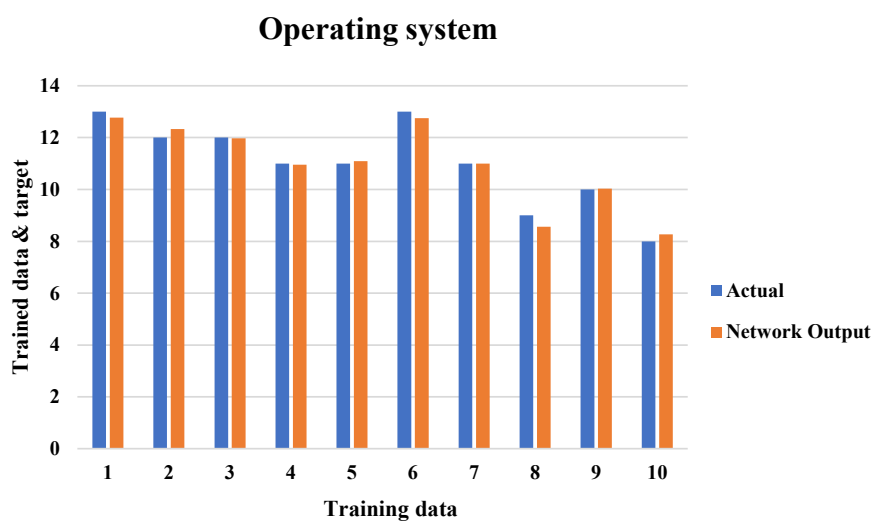

Fig. 10: Comparison between network output and target values for operating system

shows how well the data fit the regression model. We have compared the result of the ANN model with the Support Vector Regression (SVR) model [92]. SVR implementation is easy, and it exhibits good generalization ability for complex model $[93,94]$. Unlike other regression models that try to minimize the error between the actual and predicted value, the SVR tries to fit the best line within a threshold value. The threshold value is the distance between the hyperplane and the boundary line [93]. In this study, the SVR model uses the nonlinear radial basis function (RBF) kernel. The result of both models are presented in Table XIII. From Table XIII it is found that ANN performs better than SVR.

Fig. 16 to Fig. 21 show the forecast result of the ANN model and SVR model. Fig. 16 to Fig. 21 also describe the validation of the model for five sets of sample data points that were not used in training. From Fig. 16 to Fig. 21, it is found that, SVR performs better than ANN for some data points. The reason behind this can be at in the case of SVR, we predict

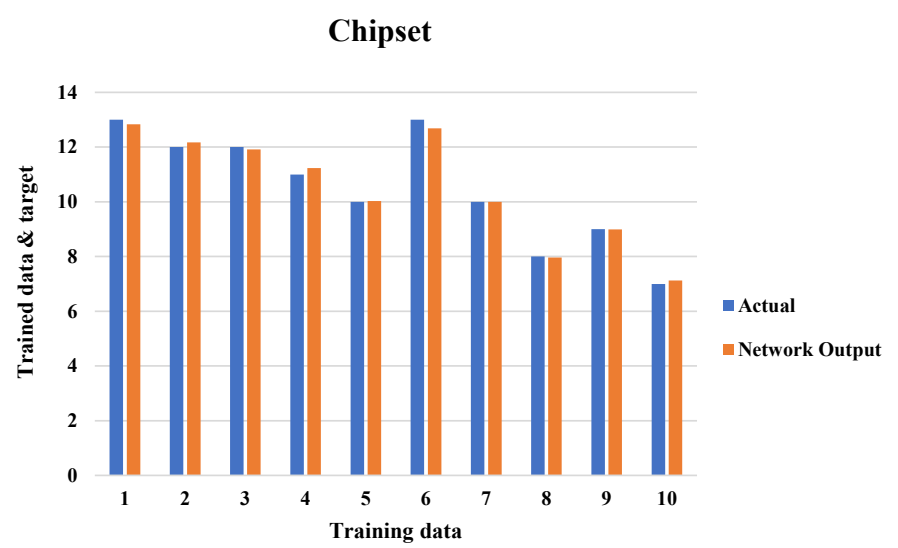

Fig. 11: Comparison between network output and target values for chipset

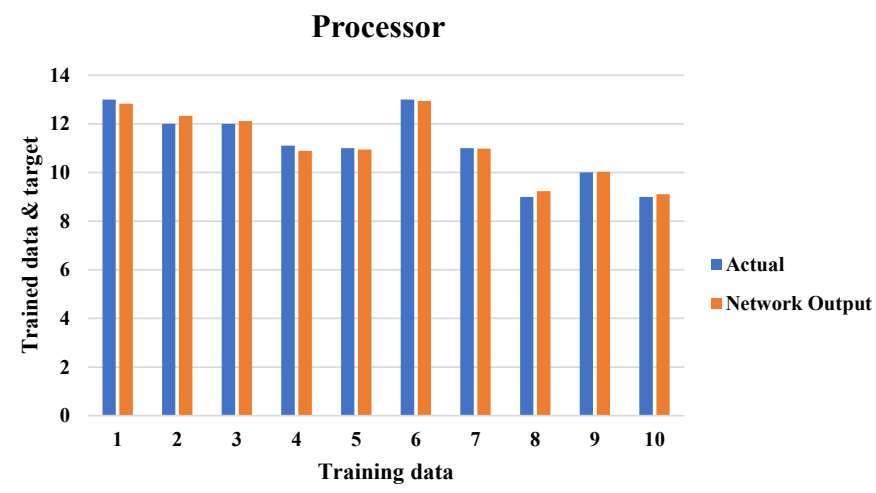

Fig. 12: Comparison between network output and target values for processor

each variable individually, whereas, in the case of ANN, we envision all variables together. Fig. 10 to Fig. 15, the Y-axis represents the number of data set used for training, and from Fig. 16 to Fig. 21, the Y-axis represents the number of data set used as sample to validate the ANN model.

Our forecasting model is motivated by the availability of information related to previous products. We can use the information on products to forecast the design specification

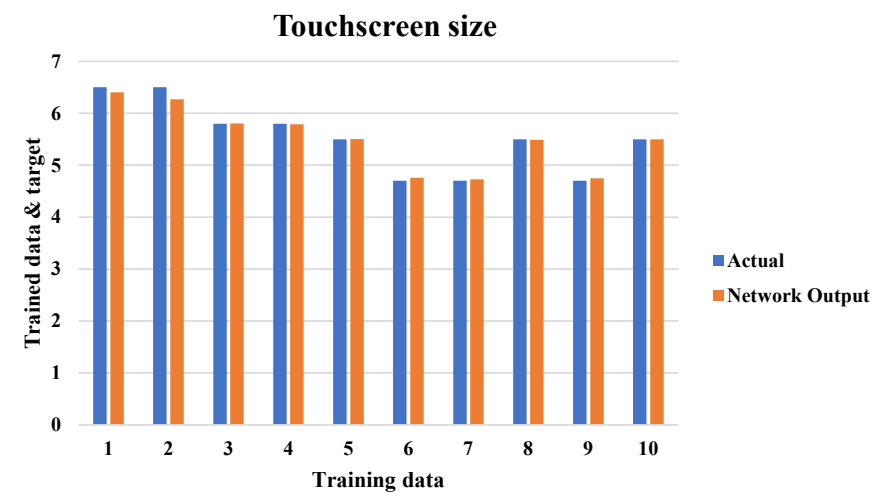

Fig. 13: Comparison between network output (touchscreen size) and target values for touchscreen size 
Touchscreen technology

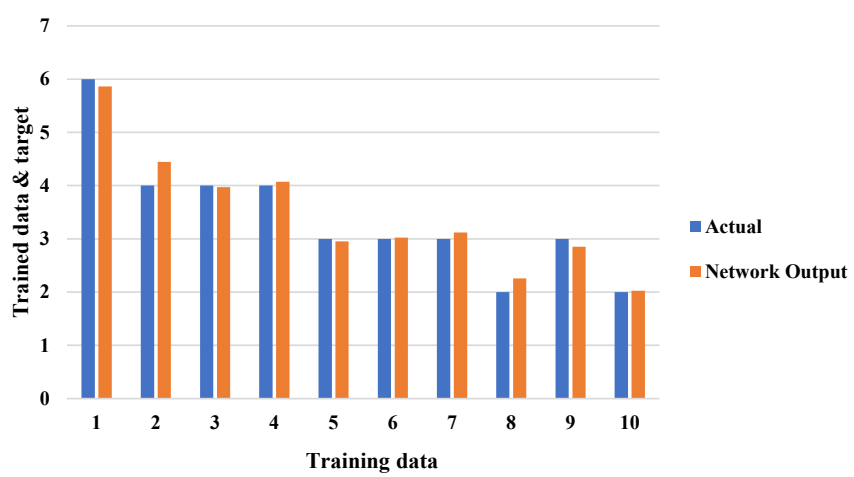

Fig. 14: Comparison between network output and target values for touchscreen technology

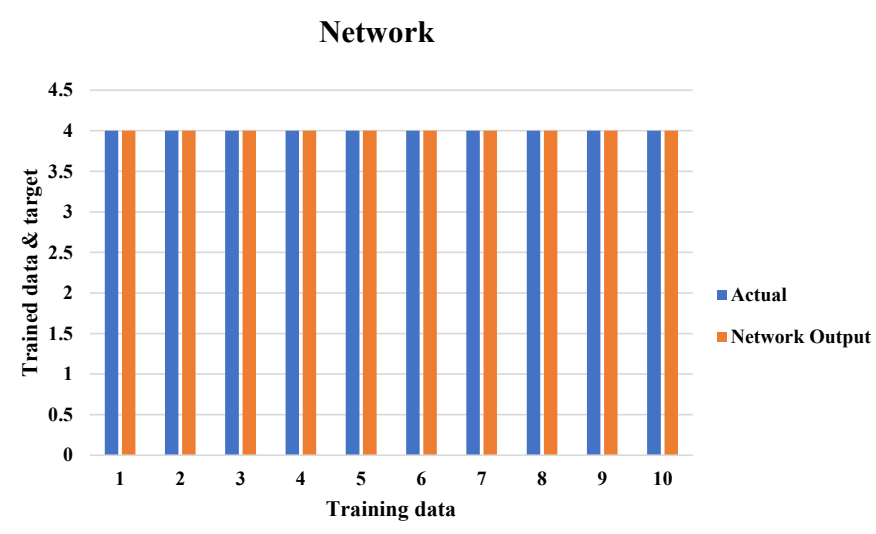

Fig. 15: Comparison between network output and target values for network

\section{Operating system}

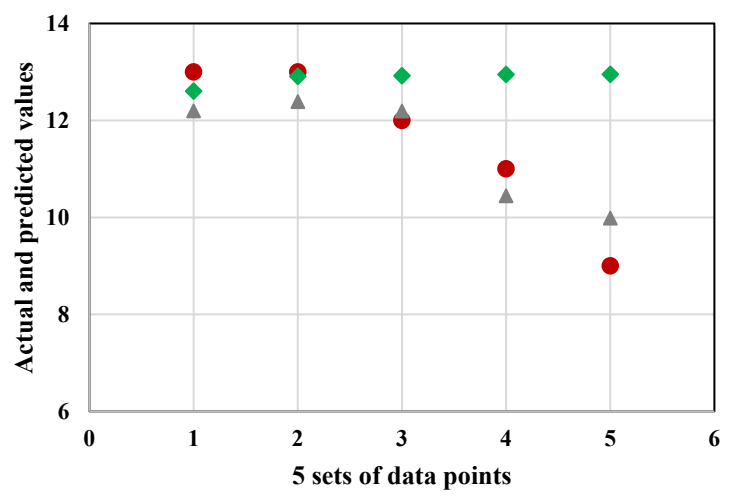

Fig. 16: The comparison of actual values and the predicted values for operating system

\section{Chipset}

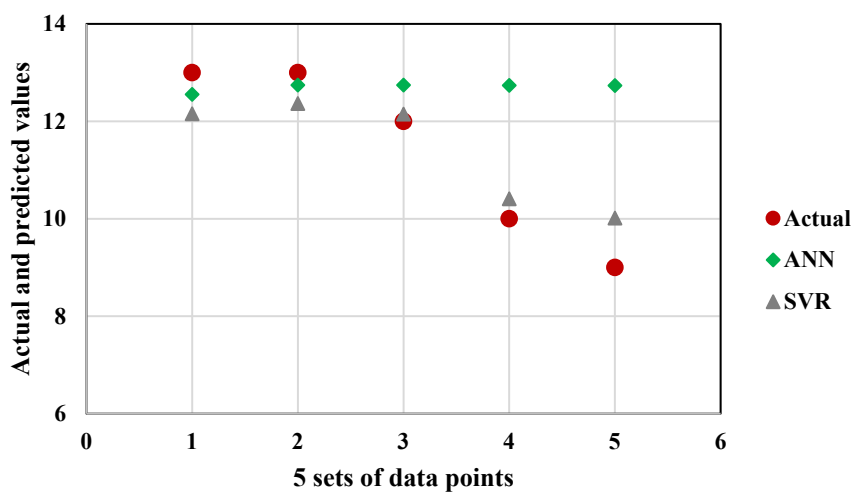

Fig. 17: The comparison of actual values and the predicted values for Chipset

\section{Processor}

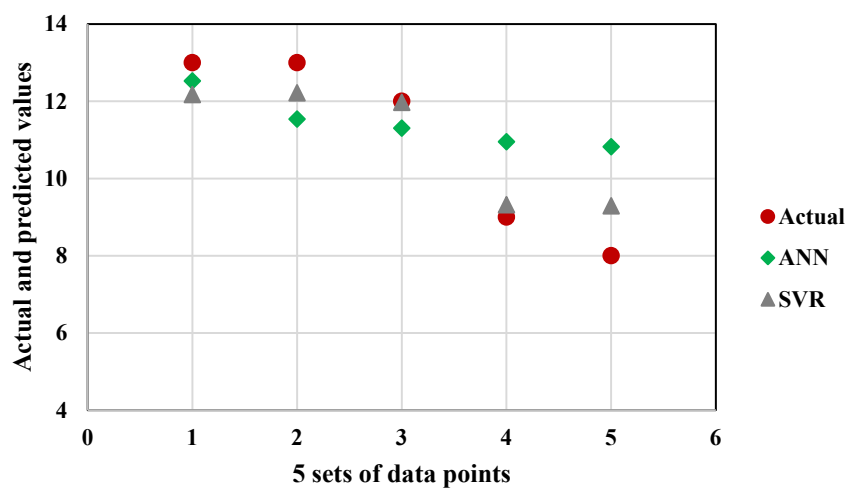

Fig. 18: The comparison of actual values and the predicted values for Processor

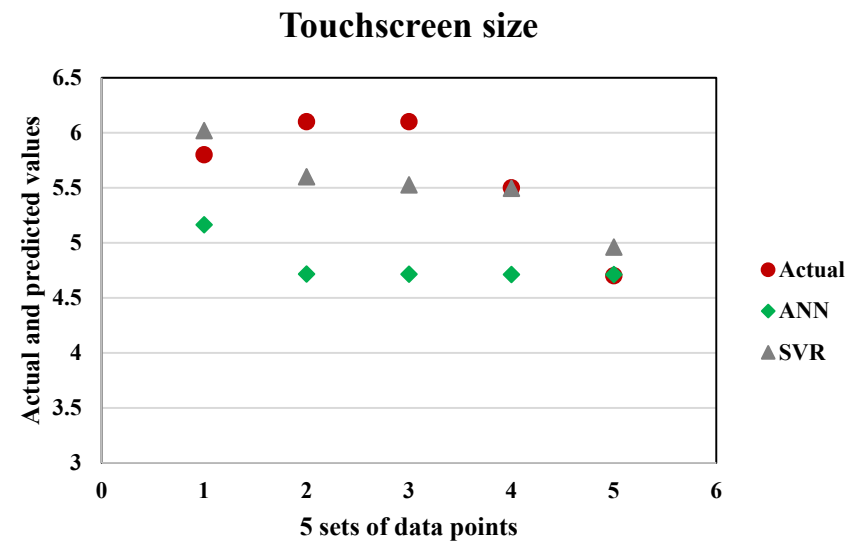

Fig. 19: The comparison of actual values and the predicted values for touchscreen size 


\section{Touchscreen technology}

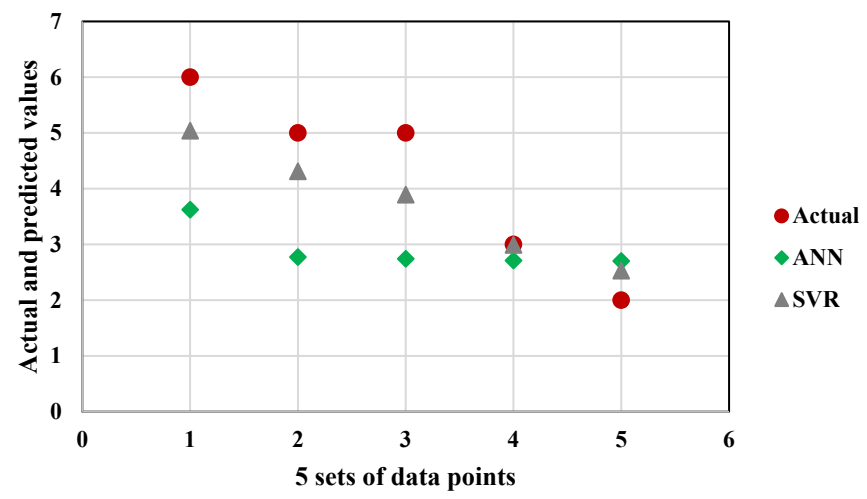

Fig. 20: The comparison of actual values and the predicted values for touchscreen technology

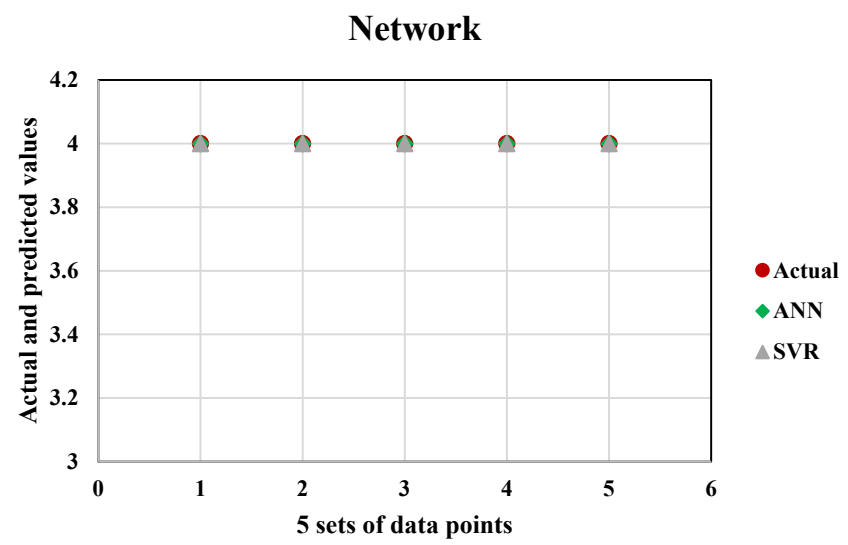

Fig. 21: The comparison of actual values and the predicted values for Network

of some key features with reasonable confidence that has significant influence on the development of future product.

In this paper, forecasting the most influential features is an example that is critical for the manager in decision-making plans for future products. By applying the same methodology, any company or industry can forecast the information regarding the specification of key design features to successfully launch a new product variant. Therefore, the proposed neural network model is used for forecasting and the results clearly show that the ANN-based forecasting model can forecast with significant accuracy.

\section{MANAGERIAL IMPLICATIONS}

From this proposed approach decision maker can be able to identify that which features were undergone through significant changes over time and has strong influence on future development of product family. Some managerial implications of this study are given below.

- This study helps managers to understand the importance of dynamic factors comparing to each other that influence the evolution of a product family.

- Based on the results of this research study, managers can pinpoint the influential features from a large number of features that have undergone through generation to generation and implement the changes in the next generation products. It also helps manager to get an idea about the specification of those features that is appropriate based on the present time.

- This study also facilitates managers to optimize the investment on $\mathrm{R} \& \mathrm{D}$ by putting emphasis on influential features that are identified by our proposed approach.

\section{COnclusions And Future Work}

A dynamic modeling method combined with a forecasting model for product family evolution with an emphasis on feature-based product family has been proposed. This research work has yielded some interesting observations for product family evolution. We reconstructed hypothetical relations of a product family and has opened new ideas regarding the evolution pattern of a product family. Our Apple iPhone case study shows that the proposed model is feasible and applicable in the engineering design of the product development system. In addition, it is also found that the forecasting model can forecast information regarding the design features with reasonable accuracy. We found that features like the Operating system, Processor, Touchscreen, Network have undergone significant changes over time and have a strong influence on the future development of the product family. Also, it is identified that the performance of a product does not always improve with the growth of generations. The proposed model incorporates the forecasting model with the evolution model which can help managers to become involved in decision making regarding the design of the future product.

There are several research avenues to extend this study. For example, an interesting future research direction would be the hybridization of the forecasting phase by coupling state-of-art machine learning algorithms with ANN to increase prediction accuracy. Another worthwhile contribution would be to use other existing fuzzy MCDM (e.g., fuzzy TOPSIS, Electre, etc.) in the evaluation phase and to complete a comparative analysis such as compare GRA and Fuzzy AHP with other techniques based on this case or different cases. In our future work, We would also like to develop a model that can address the decision-making support for innovation and creation in product evolution.

\section{DECLARATION OF COMPETING INTEREST}

These authors declare that they have no conflict of interests on the work reported in this paper.

\section{ACKNOWLEDGEMENT}

This research is supported by Capability Systems Centre, University of New South Wales, Canberra, Australia.

\section{REFERENCES}

[1] L. Hou, Y.-m. Wu, R.-s. Lai, and S. H. Huang, "Evaluation and driver analysis in product family evolution," The International Journal of Advanced Manufacturing Technology, vol. 69, no. 1-4, pp. 863-874, 2013.

[2] G. R. Massey, "Product evolution: a darwinian or lamarckian phenomenon?" Journal of Product \& Brand Management, 1999. 
[3] Dictionary.com, "Evolution." [Online]. Available: https://www. dictionary.com/browse/evolution

[4] K. Park and G. E. Okudan Kremer, "A network based dynamic model for product family evolution," in International Design Engineering Technical Conferences and Computers and Information in Engineering Conference, vol. 46353. American Society of Mechanical Engineers, 2014, p. V004T06A027.

[5] R. Kazemzadeh, M. Behzadian, M. Aghdasi, and A. Albadvi, "Integration of marketing research techniques into house of quality and product family design," The International Journal of Advanced Manufacturing Technology, vol. 41, no. 9-10, p. 1019, 2009.

[6] W. Haolun, H. Liang, and L. Yuyi, "Theoretical system of product platform innovation and evolution," in 2009 16th International Conference on Industrial Engineering and Engineering Management. IEEE, 2009, pp. $1056-1060$.

[7] G. Nadadur, M. B. Parkinson, and T. W. Simpson, "Draft: Application of the generational variety index: A retrospective study of iphone evolution," Proceedings of the ASME 2012 International Design Engineering Technical Conferences Computers and Information in Engineering conference, 2012.

[8] J. Xie, Y. Bi, Z. Sha, M. Wang, Y. Fu, N. Contractor, L. Gong, and W. Chen, "Data-driven dynamic network modeling for analyzing the evolution of product competitions," Journal of Mechanical Design, vol 142 , no. 3, 2020.

[9] B. Yoon, I. Park, and B.-y. Coh, "Exploring technological opportunities by linking technology and products: Application of morphology analysis and text mining," Technological Forecasting and Social Change, vol. 86 , pp. 287-303, 2014.

[10] G. Nadadur, W. Kim, A. R. Thomson, M. B. Parkinson, and T. W. Simpson, "Strategic product design for multiple global markets," in International Design Engineering Technical Conferences and Computers and Information in Engineering Conference, vol. 45066. American Society of Mechanical Engineers, 2012, pp. 837-848.

[11] G. Zhang, B. E. Patuwo, and M. Y. Hu, "Forecasting with artificial neural networks:: The state of the art," International journal of forecasting, vol. 14, no. 1, pp. 35-62, 1998.

[12] S. C. Wheelwright and J. W. Sasser, "The new product development map." Harvard Business Review, vol. 67, no. 3, pp. 112-125, 1989

[13] M. H. Meyer and J. M. Utterback, "The product family and the dynamics of core capability," 1992.

[14] M. Meyer and A. P. Lehnerd, "The power of product platforms: building value and cost leadership. 1997," New York, NY, vol. 10020, p. 39, 1997.

[15] J. Ohvanainen and E. Hietikko, "Building competitive advantage through platform-based product family thinking: Case powerpacks," Journal of Industrial Engineering and Management (JIEM), vol. 5, no. 1, pp. 180197, 2011.

[16] K. T. Ulrich, Product design and development. Tata McGraw-Hill Education, 2003.

[17] K. Park, "Characterization and modeling of product family evolution," 2017.

[18] X. Xu, L. Gao, and S. Fang, "Product family architecture evolution based on technology evolution theory of triz," in 2008 7th World Congress on Intelligent Control and Automation. IEEE, 2008, pp. 5662-5666.

[19] H. Liu and Ö. Özer, "Managing a product family under stochastic technological changes," International Journal of Production Economics, vol. 122, no. 2, pp. 567-580, 2009.

[20] F. Wang, S. J. Fenves, R. Sudarsan, and R. D. Sriram, "Towards modeling the evolution of product families," in International design engineering technical conferences and computers and information in engineering conference, vol. 36991, 2003, pp. 421-430.

[21] R. Dou, Y. Zhang, and G. Nan, "Iterative product design through group opinion evolution," International Journal of Production Research, vol. 55, no. 13, pp. 3886-3905, 2017.

[22] S. Filippi and D. Barattin, "Definition and exploitation of trends of evolution about interaction," Technological Forecasting and Social Change, vol. 86, pp. 216-236, 2014.

[23] W. P. Shao, Y. P. Hao, and P. F. Zeng, "Study on product family architecture dynamic evolution based on product instances," in Advanced Materials Research, vol. 472. Trans Tech Publ, 2012, pp. 2612-2616.

[24] F. Liu, S. Song, and X. Deng, "Research on evolving rule of part relation network of product family," International Journal of Materials and Structural Integrity, vol. 1, no. 4, pp. 334-343, 2008

[25] R.-B. Sui and G.-J. Zhong, "Research on degree distribution of networks of parts relationship for product family on scale-free networks," in 2008 4th International Conference on Wireless Communications, Networking and Mobile Computing. IEEE, 2008, pp. 1-4.
[26] F.-y. Liu, G.-n. Qi, and Q.-h. Yang, "Forecast method for used number of parts and components based on complex network," Frontiers of Mechanical Engineering in China, vol. 1, no. 4, pp. 479-484, 2006.

[27] Q. Le, Z. Sha, and J. H. Panchal, "A generative network model for product evolution," Journal of computing and information science in engineering, vol. 14, no. 1, 2014.

[28] S. Li, Y. Wu, Y. Xu, J. Hu, and J. Hu, "A bayesian network based adaptability design of product structures for function evolution," Applied Sciences, vol. 8, no. 4, p. 493, 2018.

[29] S.-J. Kim, J.-D. Lee, and E.-Y. Jung, "Research on the logic of product evolution using agent-based model," in 2016 Portland International Conference on Management of Engineering and Technology (PICMET). IEEE, 2016, pp. 2460-2466.

[30] T. Faragó and Á. Miklósi, "Cellphone evolution-applying evolution theory to an info-communication system," in 2012 IEEE 3rd International Conference on Cognitive Infocommunications (CogInfoCom). IEEE, 2012, pp. 763-768.

[31] H. Zhang, S. Qin, R. Li, Y. Zou, and G. Ding, "Progressive modelling of feature-centred product family development," International Journal of Production Research, vol. 58, no. 12, pp. 3701-3723, 2020.

[32] G. Cao, H. Guo, C. Zhang, H. Liu, and Q. Li, "Function evolution and forecasting for product innovation," in 2010 IEEE International Conference on Management of Innovation \& Technology. IEEE, 2010, pp. $40-44$.

[33] Y. Orbach and G. E. Fruchter, "Forecasting sales and product evolution: The case of the hybrid/electric car," Technological Forecasting and Social Change, vol. 78, no. 7, pp. 1210-1226, 2011.

[34] T. AlGeddawy and H. ElMaraghy, "A co-evolution model for prediction and synthesis of new products and manufacturing systems," Journal of Mechanical Design, vol. 134, no. 5, 2012.

[35] J. Mahanta, "Introduction to neural networks, advantages and applications," Towards Data Science, vol. 13, 2017.

[36] D. J. Sargent, "Comparison of artificial neural networks with other statistical approaches: results from medical data sets," Cancer: Interdisciplinary International Journal of the American Cancer Society, vol. 91, no. S8, pp. 1636-1642, 2001

[37] O. Claveria, E. Monte, and S. Torra, "Data pre-processing for neural network-based forecasting: does it really matter?" Technological and Economic Development of Economy, vol. 23, no. 5, pp. 709-725, 2017.

[38] T. X. Cheng, W. B. Du, and J. Z. Chen, "A short-term combination forecasting model for traffic flow based on the bp neural network," in Applied Mechanics and Materials, vol. 253. Trans Tech Publ, 2013, pp. 1339-1344.

[39] L. Bin-sheng, X. Zhan-wen, Y. Hai-tao, and H. Yu-peng, "A combination predicted model of short term traffic flow," in 2006 International Conference on Management Science and Engineering. IEEE, 2006, pp. 2075-2080.

[40] M. S. Islam, M. M. Kabir, and N. Kabir, "Artificial neural networks based prediction of insolation on horizontal surfaces for bangladesh," Procedia Technology, vol. 10, pp. 482-491, 2013.

[41] R. Ghasemiyeh, R. Moghdani, and S. S. Sana, "A hybrid artificial neural network with metaheuristic algorithms for predicting stock price," Cybernetics and Systems, vol. 48, no. 4, pp. 365-392, 2017.

[42] L. Huo, B. Jiang, T. Ning, and B. Yin, "A bp neural network predictor model for stock price," in International Conference on Intelligent Computing. Springer, 2014, pp. 362-368.

[43] P. Whitehead, A. Howard, and C. Arulmani, "Modelling algal growth and transport in rivers: a comparison of time series analysis, dynamic mass balance and neural network techniques," Hydrobiologia, vol. 349, no. 1-3, pp. 39-46, 1997.

[44] O. Obafemi, A. Stephen, O. Ajayi, and M. Nkosinathi, "A survey of artificial neural network-based prediction models for thermal properties of biomass," Procedia Manufacturing, vol. 33, pp. 184-191, 2019.

[45] S. Biswas, S. G. Anavatti, and M. A. Garratt, "Multiobjective mission route planning problem: A neural network-based forecasting model for mission planning," IEEE Transactions on Intelligent Transportation Systems, 2019.

[46] H. Lee, S. G. Kim, H.-w. Park, and P. Kang, "Pre-launch new product demand forecasting using the bass model: A statistical and machine learning-based approach," Technological Forecasting and Social Change, vol. 86, pp. 49-64, 2014.

[47] D. Golmohammadi, "Neural network application for fuzzy multi-criteria decision making problems," International Journal of Production Economics, vol. 131, no. 2, pp. 490-504, 2011.

[48] H. R. Maier and G. C. Dandy, "Neural network based modelling of environmental variables: a systematic approach," Mathematical and Computer Modelling, vol. 33, no. 6-7, pp. 669-682, 2001. 
[49] J. Montgomerie and S. Roscoe, "Owning the consumer-getting to the core of the apple business model," in Accounting Forum, vol. 37, no. 4. Elsevier, 2013, pp. 290-299.

[50] tag, "Apple, king of brand loyalty." [Online]. Available: https: //www.gettagged.us/apple-king-brand-loyalty/

[51] Tim, "The reasons behind apple's customer loyalty and high nps." [Online]. Available: https://www.retently.com/blog/apple-nps/

[52] Wikipedia, "iphone 11." [Online]. Available: https://en.wikipedia.org/ wiki/IPhone 11\#cite note-1

[53] Gsmarena, "Phone finder." [Online]. Available: https://www.gsmarena. com/apple_iphone_3g-2424.php

[54] Support.apple.com, "iphone specification." [Online]. Available: https: //support.apple.com/kb/SP767?viewlocale=en_AU\&locale=en_AU

[55] apple.com, "Compare iphone models." [Online]. Available: https://www.apple.com/au/iphone/compare/?device1=iphoneXS\& device2=iphoneXSmax\&device $3=$ iphone 11

[56] Support.apple.com, "Identify your iphone model." [Online]. Available: https://support.apple.com/en-au/HT201296

[57] bankmcell.com, "Iphone timeline: Ios iphone evolution 2007-2020." [Online]. Available: https://www.bankmycell.com/blog/ iphone-evolution-timeline-chart

[58] T. Guide, "How the price of the iphone has increased over the years." [Online]. Available: https://www.techguide.com.au/news/mobiles-news/ price-iphone-increased-years/

[59] D. Price, "New iphone se (2020) release date, price specs.” [Online]. Available: https://www.macworld.co.uk/news/iphone/ iphone-se2-3500611/

[60] S. Dayaram, "iphone se 2020 vs. 2016: Everything apple changed in the new version." [Online]. Available: https://www.cnet.com/news/ iphone-se-2020-vs-iphone-se-2016-everything-apple-changed/

[61] E. R. Vaidogas and J. Sakènaite, "Solving the problem of multiplecriteria building design decisions with respect to the fire safety of occupants: an approach based on probabilistic modelling," Mathematical Problems in Engineering, vol. 2015, 2015.

[62] A. Vidhya, "Simple methods to deal with categorical variables in predictive modeling." [Online]. Available: https://www.analyticsvidhya.com/blog/2015/11/ easy-methods-deal-categorical-variables-predictive-modeling/

[63] C. Contributor, "Difference between individual demand market demand." [Online]. Available: https://smallbusiness.chron.com/ difference-between-individual-demand-market-demand-44739.html

[64] A. Sutanto, B. Yuliandra, B. Tjahjono, and R. A. Hadiguna, "Productservice system design concept development based on product and service integration," Journal of Design Research, vol. 13, no. 1, pp. 1-19, 2015.

[65] H. Ehlhardt, "Product evolution diagram; a systematic approach used in evolutionary product development," in DS 76: Proceedings of E\&PDE 2013, the 15th International Conference on Engineering and Product Design Education, Dublin, Ireland, 05-06.09. 2013, 2013.

[66] Bioninja, "Pedigree charts." [Online]. Available: https://ib.bioninja.com. au/standard-level/topic-3-genetics/34-inheritance/pedigree-charts.html

[67] G. Science, "Pedigree charts." [Online]. Available: https://www. goodscience.com.au/year-10-biology/pedigree-charts/

[68] D. Ju-Long, "Control problems of grey systems," Systems \& control letters, vol. 1 , no. 5, pp. 288-294, 1982.

[69] J. Morán, E. Granada, J. Míguez, and J. Porteiro, "Use of grey relational analysis to assess and optimize small biomass boilers," Fuel Processing Technology, vol. 87, no. 2, pp. 123-127, 2006.

[70] Y. Kuo, T. Yang, and G.-W. Huang, "The use of grey relational analysis in solving multiple attribute decision-making problems," Computers \& industrial engineering, vol. 55, no. 1, pp. 80-93, 2008.

[71] J. Dai, X. Liu, and F. Hu, "Research and application for grey relational analysis in multigranularity based on normality grey number," The Scientific World Journal, vol. 2014, 2014.

[72] H.-H. Wu, "A comparative study of using grey relational analysis in multiple attribute decision making problems," Quality Engineering, vol. 15, no. 2, pp. 209-217, 2002.

[73] Z. Wang, S. Liu, and H. Ren, "Sensitivity analysis of grey relational ordering," in 2007 IEEE International Conference on Systems, Man and Cybernetics. IEEE, 2007, pp. 2210-2214.

[74] S. A. Javed, A. M. Khan, W. Dong, A. Raza, and S. Liu, "Systems evaluation through new grey relational analysis approach: an application on thermal conductivity - petrophysical parameters' relationships," Processes, vol. 7, no. 6, p. 348, 2019.

[75] Y. Cenglin, "Application of gray relational analysis method in comprehensive evaluation on the customer satisfaction of automobile $4 \mathrm{~s}$ enterprises," Physics Procedia, vol. 33, pp. 1184-1189, 2012.
[76] U. Çaydaş and A. Hasçalık, "Use of the grey relational analysis to determine optimum laser cutting parameters with multi-performance characteristics," Optics \& laser technology, vol. 40, no. 7, pp. 987-994, 2008.

[77] C.-K. Chang and H. Lu, "Design optimization of cutting parameters for side milling operations with multiple performance characteristics," The International Journal of Advanced Manufacturing Technology, vol. 32, no. 1-2, pp. 18-26, 2007.

[78] M. S. Pakkar, "An integrated approach to grey relational analysis, analytic hierarchy process and data envelopment analysis," Journal of Centrum Cathedra, 2016

[79] B. C. Balusa and A. K. Gorai, "Sensitivity analysis of fuzzy-analytic hierarchical process (fahp) decision-making model in selection of underground metal mining method," Journal of Sustainable Mining, vol. 18 , no. 1 , pp. 8-17, 2019.

[80] A. Minns and M. Hall, "Artificial neural networks as rainfall-runoff models," Hydrological sciences journal, vol. 41, no. 3, pp. 399-417, 1996.

[81] MathWorks, "nntool." [Online]. Available: https://au.mathworks.com/ help/deeplearning/ref/nntool.html

[82] H. F. Rahman, R. K. Chakrabortty, and M. J. Ryan, "Memetic algorithm for solving resource constrained project scheduling problems," Automation in Construction, vol. 111, p. 103052, 2020.

[83] MathWorks, "tansig." [Online]. Available: https://au.mathworks.com/ help/deeplearning/ref/tansig.html

[84] B. Devenish, P. Francis, B. Johnson, R. Sparks, and D. Thomson, "Sensitivity analysis of dispersion modeling of volcanic ash from eyjafjallajökull in may 2010," Journal of Geophysical Research: Atmospheres, vol. 117, no. D20, 2012.

[85] F. Pianosi, K. Beven, J. Freer, J. W. Hall, J. Rougier, D. B. Stephenson, and T. Wagener, "Sensitivity analysis of environmental models: A systematic review with practical workflow," Environmental Modelling \& Software, vol. 79, pp. 214-232, 2016.

[86] A. Anand, M. Agrawal, N. Bhatt, and M. Ram, "Software patch scheduling policy incorporating functional safety standards," in Advances in System Reliability Engineering. Elsevier, 2019, pp. 267-279.

[87] F. Paton, H. Maier, and G. Dandy, "Relative magnitudes of sources of uncertainty in assessing climate change impacts on water supply security for the southern adelaide water supply system," Water Resources Research, vol. 49, no. 3, pp. 1643-1667, 2013.

[88] MktgStudyGuid, "How to make a mds map from start to finish (video)." [Online]. Available: https://www.perceptualmaps.com/free-templates/ multidimensional-perceptual-maps/multi-attribute-perceptual-maps/ make-mds-map-start-finish-video/

[89] A. M. Zain, H. Haron, and S. Sharif, "Prediction of surface roughness in the end milling machining using artificial neural network," Expert Systems with Applications, vol. 37, no. 2, pp. 1755-1768, 2010.

[90] Y. Zhang, H. Chen, B. Yang, S. Fu, J. Yu, and Z. Wang, "Prediction of phosphate concentrate grade based on artificial neural network modeling," Results in Physics, vol. 11, pp. 625-628, 2018.

[91] MathWorks, "Choose a multilayer neural network training function." [Online]. Available: https://au.mathworks.com/help/deeplearning/ug/ choose-a-multilayer-neural-network-training-function.html

[92] M. Awad and R. Khanna, "Support vector regression," in Efficient learning machines. Springer, 2015, pp. 67-80.

[93] U. Thissen, R. Van Brakel, A. De Weijer, W. Melssen, and L. Buydens, "Using support vector machines for time series prediction," Chemometrics and intelligent laboratory systems, vol. 69, no. 1-2, pp. 35-49, 2003.

[94] A. Raj, "Unlocking the true power of support vector regression," 2020. [Online]. Available: https://towardsdatascience.com/ unlocking-the-true-power- of-support-vector-regression-847fd123a4a0

[95] F.-y. Zhang and Y.-s. Xu, "Research on technical strategy for new product development based on triz evolution theory," International Journal of Product Development, vol. 4, no. 1-2, pp. 96-108, 2007.

[96] S. Rudolf, C. Ortlieb, C. Tönnes, and G. Schuh, "Discovering product innovation potential within existing product architectures," in Applied Mechanics and Materials, vol. 794. Trans Tech Publ, 2015, pp. 540546.

\section{APPENDIX}

\section{A. Appendix A}


TABLE A.1: Literature related to product family evolution

\begin{tabular}{|c|c|c|c|c|c|}
\hline Approach & Methods & Literature & Description & Drive force & Case study \\
\hline \multirow{21}{*}{$\begin{array}{l}\text { Product } \\
\text { family } \\
\text { evolution }\end{array}$} & $\begin{array}{l}\text { Dynamic modeling } \\
\text { framework }\end{array}$ & Xu et al. [18] & $\begin{array}{l}\text { Technology evolu- } \\
\text { tion theory of TRIZ } \\
\text { and a complex net- } \\
\text { work theory }\end{array}$ & Customer requirements & No \\
\hline & $\begin{array}{l}\text { A decision frame- } \\
\text { work }\end{array}$ & Liu and Ozer [19] & $\begin{array}{l}\text { Markov decision } \\
\text { model }\end{array}$ & Technological changes & Numerical example \\
\hline & $\begin{array}{l}\text { Function evolution } \\
\text { and forecasting }\end{array}$ & Cao et al. [32] & $\begin{array}{l}\text { TRIZ tools and CAI } \\
\text { software }\end{array}$ & $\begin{array}{l}\text { Market and technology } \\
\text { analysis }\end{array}$ & $\begin{array}{l}\text { Innovative design of } \\
\text { pill degreasing ma- } \\
\text { chine }\end{array}$ \\
\hline & Dynamic modeling & Hou et al. [1] & $\begin{array}{l}\text { Gray conjunction } \\
\text { Degree }\end{array}$ & $\begin{array}{l}\text { Dynamic market, lev- } \\
\text { els of design, technology } \\
\text { and management, tech- } \\
\text { nological advancement }\end{array}$ & $\begin{array}{l}\text { Small wheel loaders } \\
\text { (SWLs) }\end{array}$ \\
\hline & $\begin{array}{l}\text { Framework model- } \\
\text { ing }\end{array}$ & Liu et al. [26] & Complex network & Customer satisfaction & Steam turbine \\
\hline & Evolving Rules & Liu et al. [24] & Complex network & & No \\
\hline & $\begin{array}{ll}\text { Dynamic } & \text { network } \\
\text { modeling } & \\
\end{array}$ & Park \& Kremer [4] & $\begin{array}{ll}\text { Network } & \text { science } \\
\text { approach } & \\
\end{array}$ & $\begin{array}{l}\text { Different market niches } \\
\text { and customer needs }\end{array}$ & No \\
\hline & $\begin{array}{l}\text { Product family net- } \\
\text { work }\end{array}$ & Sui et al. [25] & $\begin{array}{l}\text { Scale-free networks } \\
\text { (Barabàsi and Al- } \\
\text { bert (BA) model) }\end{array}$ & & No \\
\hline & $\begin{array}{l}\text { Generative model- } \\
\text { ing }\end{array}$ & Le et al. [27] & $\begin{array}{l}\text { Network } \\
\text { mechanism }\end{array}$ & & \begin{tabular}{lr} 
Software & \multicolumn{2}{c}{ product } \\
(Drupal) & and a \\
physical & product \\
(RepRap & 3D \\
printer) &
\end{tabular} \\
\hline & Logic modeling & Kim et al. [29] & Agent based model & $\begin{array}{l}\text { Producer's routine, cus- } \\
\text { tomer's preference and } \\
\text { complementarity of the } \\
\text { product features }\end{array}$ & No \\
\hline & Dynamic modeling & Duo et al. [21] & $\begin{array}{l}\text { Hegselmann } \\
\text { Krause model }\end{array}$ & $\begin{array}{l}\text { Customers' opinions, } \\
\text { professional designers' } \\
\text { opinions and the product } \\
\text { scheme }\end{array}$ & No \\
\hline & $\begin{array}{l}\text { Data driven } \\
\text { Dynamic model }\end{array}$ & Li et al. [28] & Bayesian Network & $\begin{array}{l}\text { customer satisfaction, } \\
\text { manufacturing cost, sale } \\
\text { price, market sales and } \\
\text { indirect factors }\end{array}$ & Electric toothbrush \\
\hline & Retrospective study & Nadadur et al. [10] & $\begin{array}{l}\text { Generational } \\
\text { variety index (GVI) }\end{array}$ & $\begin{array}{l}\text { Market life, customer re- } \\
\text { quirements }\end{array}$ & $\begin{array}{l}\text { iPhone (1st five } \\
\text { generations) }\end{array}$ \\
\hline & $\begin{array}{l}\text { Product } \\
\text { development study }\end{array}$ & $\begin{array}{ll}\text { Farago } & \& \\
\text { Miklosi [30] } & \\
\end{array}$ & Evolution theory & Technological progress & Cellphone (Nokia) \\
\hline & $\begin{array}{l}\text { Forecasting sales } \\
\text { and product } \\
\text { (technology) } \\
\text { evolution }\end{array}$ & $\begin{array}{ll}\text { Orbach } & \text { and } \\
\text { Fruchter [33] } & \end{array}$ & $\begin{array}{l}\text { Product } \\
\text { improvements } \\
\text { based on R\&D }\end{array}$ & $\begin{array}{ll}\text { Technology, } & \text { market } \\
\text { growth, } & \text { market } \\
\text { preferences } & \end{array}$ & Hybrid car \\
\hline & $\begin{array}{l}\text { New product devel- } \\
\text { opment }\end{array}$ & Zhang et al. [95] & $\begin{array}{l}\text { TRIZ evolution the- } \\
\text { ory }\end{array}$ & $\begin{array}{lr}\text { Compitative } & \text { market } \\
\text { force \& } & \text { technology } \\
\text { changes }\end{array}$ & $\begin{array}{l}\text { Hydrodynamic } \\
\text { reciprocating seal }\end{array}$ \\
\hline & $\begin{array}{l}\text { Co-evolution model } \\
\text { (predicting new sys- } \\
\text { tems and products) }\end{array}$ & $\begin{array}{l}\text { AlGeddawy and El- } \\
\text { Maraghy [34] }\end{array}$ & $\begin{array}{l}\text { Cladistics and trees } \\
\text { reconciliation tech- } \\
\text { niques }\end{array}$ & & $\begin{array}{l}\text { Milling machine } \\
\text { tools }\end{array}$ \\
\hline & $\begin{array}{l}\text { Mapping for prod- } \\
\text { uct innovation }\end{array}$ & Rudolf et al. [96] & Cladistics & & No \\
\hline & $\begin{array}{l}\text { Progressive model- } \\
\text { ing }\end{array}$ & Zhang et al. [31] & Feature centered & $\begin{array}{l}\text { Market conditions and } \\
\text { customer demands }\end{array}$ & $\begin{array}{l}\text { High speed train's } \\
\text { bogie }\end{array}$ \\
\hline & $\begin{array}{l}\text { Characterization } \\
\text { and Modeling }\end{array}$ & Kijung Park [17] & $\begin{array}{ll}\text { Network } & \text { science } \\
\text { approach } & \end{array}$ & $\begin{array}{l}\text { Different market niches } \\
\text { and customer needs }\end{array}$ & Smartphone \\
\hline & Dynamic modeling & Xie et al. [8] & $\begin{array}{l}\text { Network based ap- } \\
\text { proach }\end{array}$ & $\begin{array}{l}\text { Market competitions and } \\
\text { customer needs }\end{array}$ & $\begin{array}{l}\text { China's automotive } \\
\text { market }\end{array}$ \\
\hline
\end{tabular}


TABLE A.2: LIST OF APPLE iPhone PRODUCTS

\begin{tabular}{cccc}
\hline Number & Model & Release date & Discontinued dates \\
\hline 1 & iPhone & June 2007 & July 2008 \\
2 & iPhone 3G & June 2008 2010 \\
3 & iPhone 3GS & June 2009 & September 2012 \\
4 & iPhone 4 & January 2010 & September 2013 \\
5 & iPhone 4S & October 2011 & September 2014 \\
6 & iPhone 5 & September 2012 & September 2013 \\
7 & iPhone 5C & September 2013 & September 2015 \\
8 & iPhone 5S & September 2013 & March 2016 \\
9 & iPhone 6 & September 2014 & September 2016 \\
10 & iPhone 6 Plus & September 2014 & September 2016 \\
11 & iPhone 6S & September 2015 & September 2018 \\
12 & iPhone 6S Plus & September 2015 & September 2018 \\
13 & iPhone SE & March 2016 & September 2018 \\
14 & iPhone 7 & September 2016 & September 2019 \\
15 & iPhone 7 Plus & September 2016 & September 2019 \\
16 & iPhone 8 & September 2017 & April 2020 \\
17 & iPhone 8 Plus & September 2017 & April 2020 \\
18 & iPhone X & November 2017 & September 2018 \\
19 & iPhone XS & September 2018 & September 2019 \\
20 & iPhone XS Max & September 2018 & September 2019 \\
21 & iPhone XR & October 2018 & In production \\
22 & iPhone 11 & September 2019 & In production \\
23 & iPhone 11 Pro & September 2019 & In production \\
24 & iPhone 11 Pro Max & September 2019 & In production \\
25 & iPhone SE (2nd Gen.) & April 2020 & In production \\
\hline
\end{tabular}

TABLE A.3: The results of grey relational grade and rank of each feature after varying the relationship matrix during the evaluation of design features

\begin{tabular}{|c|c|c|c|c|c|c|c|c|c|}
\hline $\begin{array}{c}\text { Feature } \\
\text { No. }\end{array}$ & $\begin{array}{l}\text { Feature } \\
\text { name }\end{array}$ & Grade/Rank & Actual & Scenario 1 & Scenario 2 & Scenario 3 & Scenario 4 & Scenario 5 & Scenario 6 \\
\hline \multirow[t]{2}{*}{$\mathrm{F} 1$} & \multirow{2}{*}{ Processor } & Grade & 0.842143 & 0.853738 & 0.774641 & 0.842158 & 0.842059 & 0.91648 & 0.81609 \\
\hline & & Rank & 2 & 2 & 3 & 2 & 2 & 1 & 2 \\
\hline \multirow{2}{*}{$\mathrm{F} 2$} & \multirow{2}{*}{ Touchscreen } & Grade & 0.784533 & 0.820069 & 0.735039 & 0.784551 & 0.78446 & 0.78453 & 0.75192 \\
\hline & & Rank & 4 & 3 & 4 & 4 & 4 & 4 & 4 \\
\hline \multirow[t]{2}{*}{ F3 } & \multirow{2}{*}{ Software } & Grade & 0.84741 & 0.877108 & 0.815433 & 0.847424 & 0.87814 & 0.84741 & 0.82167 \\
\hline & & Rank & 1 & 1 & 1 & 1 & 1 & 2 & 1 \\
\hline \multirow[t]{2}{*}{$\mathrm{F} 4$} & \multirow{2}{*}{ Data transfer } & Grade & 0.797322 & 0.816201 & 0.708875 & 0.797339 & 0.79725 & 0.79732 & 0.76554 \\
\hline & & Rank & 3 & 5 & 7 & 3 & 3 & 3 & 3 \\
\hline \multirow[t]{2}{*}{ F5 } & \multirow{2}{*}{ Outer casing } & Grade & 0.78318 & 0.818751 & 0.724285 & 0.783199 & 0.783108 & 0.78318 & 0.74873 \\
\hline & & Rank & 5 & 4 & 5 & 5 & 5 & 5 & 5 \\
\hline \multirow[t]{2}{*}{ F6 } & \multirow{2}{*}{ Physical interface } & Grade & 0.766092 & 0.781455 & 0.80719 & 0.766112 & 0.766023 & 0.76609 & 0.73015 \\
\hline & & Rank & 6 & 7 & 2 & 6 & 6 & 6 & 6 \\
\hline \multirow[t]{2}{*}{ F7 } & \multirow{2}{*}{ Internet connectivity } & Grade & 0.7642 & 0.789358 & 0.710984 & 0.764219 & 0.76413 & 0.76419 & 0.72896 \\
\hline & & Rank & 7 & 6 & 6 & 7 & 7 & 7 & 7 \\
\hline \multirow[t]{2}{*}{ F8 } & \multirow{2}{*}{ GPU } & Grade & 0.742435 & 0.736384 & 0.536479 & 0.7424557 & 0.74237 & 0.742435 & 0.705509 \\
\hline & & Rank & 8 & 10 & 13 & 8 & 8 & 8 & 8 \\
\hline \multirow[t]{2}{*}{ F9 } & \multirow{2}{*}{ Display } & Grade & 0.730529 & 0.751252 & 0.579941 & 0.730551 & 0.730466 & 0.73053 & 0.69141 \\
\hline & & Rank & 9 & 9 & 9 & 9 & 9 & 9 & 10 \\
\hline \multirow[t]{2}{*}{ F10 } & \multirow{2}{*}{ Flash memory } & Grade & 0.716295 & 0.765992 & 0.660436 & 0.716317 & 0.716234 & 0.71629 & 0.678391 \\
\hline & & Rank & 10 & 8 & 8 & 10 & 10 & 10 & 12 \\
\hline \multirow[t]{2}{*}{ F11 } & \multirow{2}{*}{ DRAM memory } & Grade & 0.666204 & 0.704022 & 0.568235 & 0.666228 & 0.66615 & 0.66621 & 0.624139 \\
\hline & & Rank & 11 & 11 & 11 & 11 & 11 & 11 & 13 \\
\hline \multirow[t]{2}{*}{ F12 } & \multirow{2}{*}{ Battery } & Grade & 0.664715 & 0.700826 & 0.547546 & 0.664739 & 0.66466 & 0.664715 & 0.621558 \\
\hline & & Rank & 12 & 12 & 12 & 12 & 12 & 12 & 14 \\
\hline \multirow[t]{2}{*}{ F13 } & \multirow{2}{*}{ Camera } & Grade & 0.609986 & 0.648726 & 0.579367 & 0.664319 & 0.60994 & 0.60999 & 0.563901 \\
\hline & & Rank & 13 & 13 & 10 & 13 & 13 & 13 & 15 \\
\hline \multirow[t]{2}{*}{ F14 } & \multirow{2}{*}{ GPS } & Grade & 0.394486 & 0.424646 & 0.348053 & 0.3945137 & 0.39447 & 0.39448 & 0.349013 \\
\hline & & Rank & 14 & 14 & 14 & 14 & 14 & 14 & 16 \\
\hline F15 & & Grade & 0.349068 & 0.347678 & 0.344167 & 0.349094 & 0.34905 & 0.349068 & 0.69509 \\
\hline & Sound system & Rank & 15 & 16 & 15 & 15 & 15 & 15 & 9 \\
\hline F16 & & Grade & 0.34573 & 0.424479 & 0.344001 & 0.345755 & 0.34572 & 0.34573 & 0.691038 \\
\hline & Screen protector & Rank & 16 & 15 & 16 & 16 & 16 & 16 & 11 \\
\hline
\end{tabular}


TABLE A.4: The results of grey relational grade and rank of each feature after varying the importance matrix for design features evaluation

\begin{tabular}{|c|c|c|c|c|c|c|c|c|}
\hline $\begin{array}{c}\text { Feature } \\
\text { No. }\end{array}$ & $\begin{array}{l}\text { Feature } \\
\text { name }\end{array}$ & Grade/Rank & Actual & Scenario 1 & Scenario 2 & Scenario 3 & Scenario 4 & Scenario 5 \\
\hline \multirow[t]{2}{*}{ F1 } & \multirow{2}{*}{ Processor } & Grade & 0.842158 & 0.842854 & 0.846082 & 0.845093 & 0.843434 & 0.843224 \\
\hline & & Rank & 2 & 2 & 2 & 2 & 2 & 2 \\
\hline \multirow[t]{2}{*}{$\mathrm{F} 2$} & \multirow{2}{*}{ Touchscreen } & Grade & 0.784551 & 0.78325 & 0.78165 & 0.781573 & 0.782686 & 0.782304 \\
\hline & & Rank & 3 & 3 & 5 & 5 & 3 & 3 \\
\hline \multirow[t]{2}{*}{ F3 } & \multirow{2}{*}{ Software } & Grade & 0.847424 & 0.847819 & 0.850993 & 0.852345 & 0.853074 & 0.853314 \\
\hline & & Rank & 1 & 1 & 1 & 1 & 1 & 1 \\
\hline \multirow[t]{2}{*}{$\mathrm{F} 4$} & \multirow{2}{*}{ Data transfer } & Grade & 0.781215 & 0.781789 & 0.783242 & 0.783461 & 0.778769 & 0.778769 \\
\hline & & Rank & 5 & 5 & 3 & 3 & 5 & 5 \\
\hline \multirow[t]{2}{*}{ F5 } & \multirow{2}{*}{ Outer casing } & Grade & 0.783199 & 0.782601 & 0.78197 & 0.78262 & 0.781517 & 0.78129 \\
\hline & & Rank & 4 & 4 & 4 & 4 & 4 & 4 \\
\hline \multirow[t]{2}{*}{ F6 } & \multirow{2}{*}{ Physical interface } & Grade & 0.781215 & 0.766273 & 0.764961 & 0.765432 & 0.763889 & 0.763794 \\
\hline & & Rank & 6 & 6 & 7 & 7 & 7 & 7 \\
\hline \multirow[t]{2}{*}{ F7 } & \multirow{2}{*}{ Internet connectivity } & Grade & 0.764219 & 0.764448 & 0.765532 & 0.766387 & 0.766396 & 0.766432 \\
\hline & & Rank & 7 & 7 & 6 & 6 & 6 & 6 \\
\hline \multirow[t]{2}{*}{ F8 } & \multirow{2}{*}{ GPU } & Grade & 0.742455 & 0.743046 & 0.745748 & 0.744393 & 0.745734 & 0.745546 \\
\hline & & Rank & 8 & 8 & 8 & 8 & 8 & 8 \\
\hline \multirow[t]{2}{*}{ F9 } & \multirow{2}{*}{ Display } & Grade & 0.731193 & 0.729696 & 0.727026 & 0.725081 & 0.724364 & 0.724083 \\
\hline & & Rank & 9 & 9 & 9 & 9 & 9 & 9 \\
\hline \multirow[t]{2}{*}{ F10 } & \multirow{2}{*}{ Flash memory } & Grade & 0.688162 & 0.689074 & 0.69222 & 0.692704 & 0.692874 & 0.692928 \\
\hline & & Rank & 10 & 10 & 10 & 10 & 10 & 10 \\
\hline \multirow[t]{2}{*}{ F11 } & \multirow{2}{*}{ DRAM memory } & Grade & 0.684353 & 0.685825 & 0.688248 & 0.687923 & 0.687622 & 0.68758 \\
\hline & & Rank & 11 & 11 & 11 & 11 & 11 & 11 \\
\hline \multirow[t]{2}{*}{ F12 } & \multirow{2}{*}{ Battery } & Grade & 0.664739 & 0.664757 & 0.66232 & 0.663866 & 0.662932 & 0.662978 \\
\hline & & Rank & 12 & 12 & 12 & 12 & 12 & 12 \\
\hline \multirow[t]{2}{*}{ F13 } & \multirow{2}{*}{ Camera } & Grade & 0.610012 & 0.610101 & 0.609935 & 0.61036 & 0.609819 & 0.610524 \\
\hline & & Rank & 13 & 13 & 13 & 13 & 13 & 13 \\
\hline \multirow[t]{2}{*}{ F14 } & \multirow{2}{*}{ GPS } & Grade & 0.394513 & 0.394346 & 0.394517 & 0.39469 & 0.394499 & 0.395018 \\
\hline & & Rank & 14 & 14 & 14 & 14 & 14 & 14 \\
\hline F15 & & Grade & 0.349094 & 0.34917 & 0.349117 & 0.349246 & 0.34903 & 0.349529 \\
\hline & Sound system & Rank & 15 & 15 & 15 & 15 & 15 & 15 \\
\hline F16 & & Grade & 0.345755 & 0.345953 & 0.346033 & 0.346238 & 0.346212 & 0.346193 \\
\hline & Screen protector & Rank & 16 & 16 & 16 & 16 & 16 & 16 \\
\hline
\end{tabular}


B. Appendix $B$

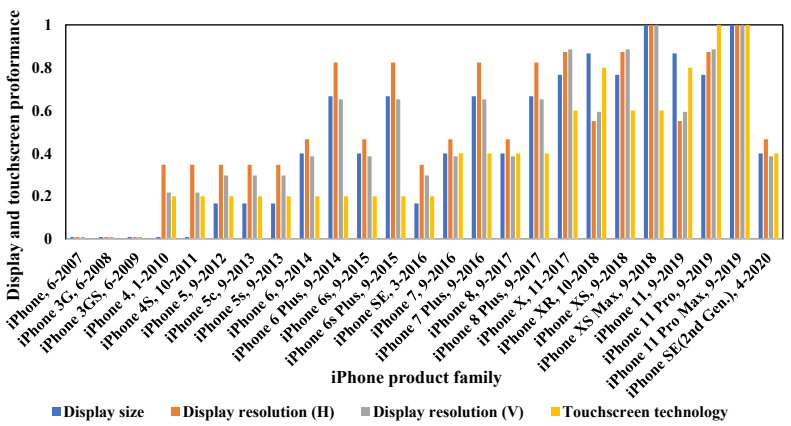

Fig. B.1: Display and touchscreen performance analysis

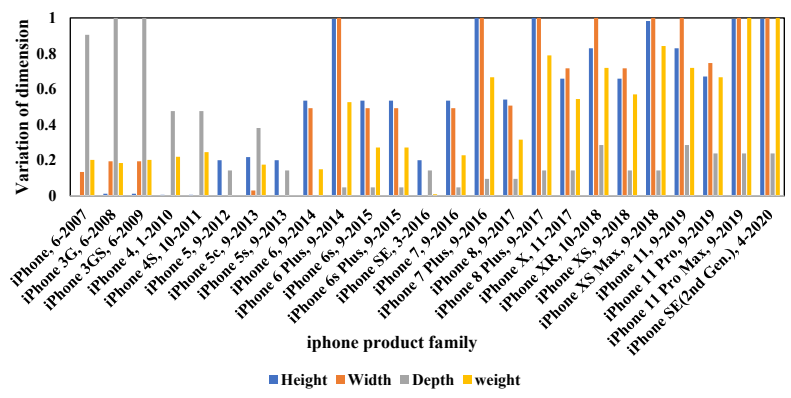

Fig. B.2: Dimension data analysis of iPhone products

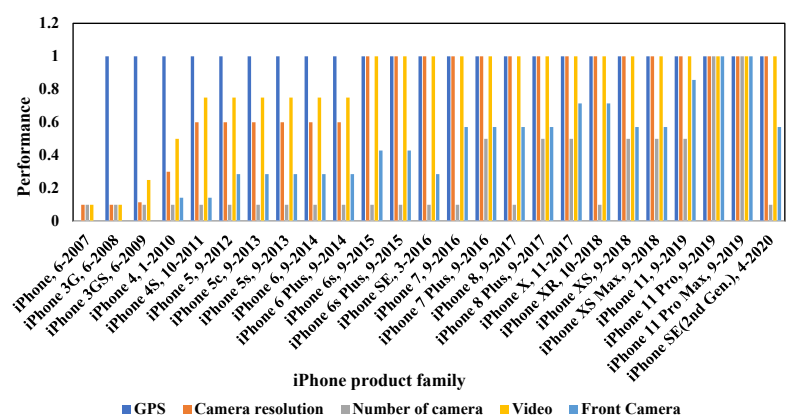

Fig. B.3: Camera and GPS performance analysis of iPhone products

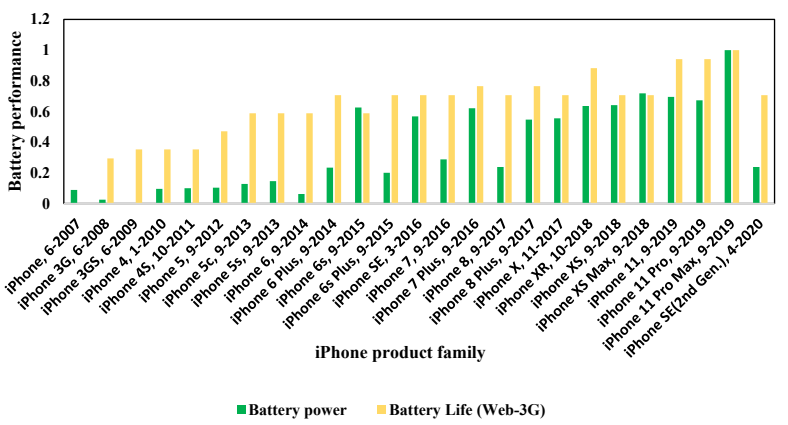

Fig. B.4: Battery performance analysis of iPhone products 


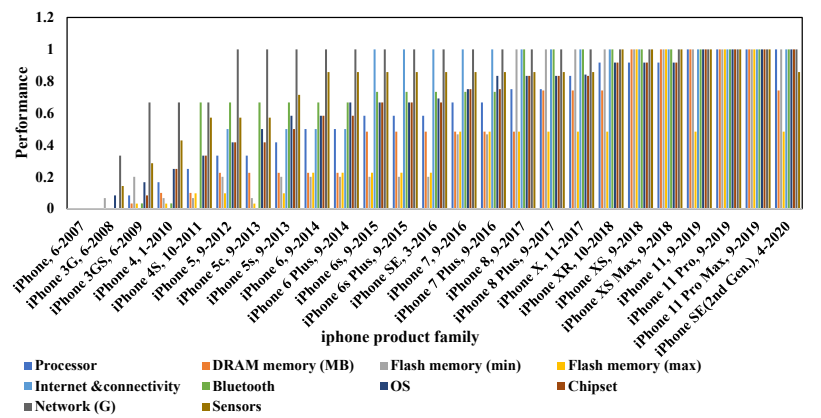

Fig. B.5: Performance analysis of different iPhone features 